\title{
Splash with A Teammate: Peer Effects in High-Stakes Tournaments*
}

\author{
Lingqing Jiang, University of Essex ${ }^{\dagger}$
}

January 7, 2020

\begin{abstract}
This paper investigates peer effects among high-skilled individuals in competitive environments with high-stakes incentives. I use data from the Swimming World Championships and study whether having a teammate in the competing group affects individual performance. The identification challenge lies in that the competing group's composition is endogenous to individual performance. I apply a regression discontinuity design by comparing finalists' performance when their teammate barely qualified or not qualified for the same finals. Female athletes accompanied by a teammate finished with less time and performed 0.8 to 1.18 ranks better in the finals. Male athletes' performance is unaffected. The potential mechanisms of enhanced intra-team competition and mitigated psychosocial pressure are discussed and are in line with literature on gender differences.
\end{abstract}

Keywords: Peer Effects, Tournaments, Regression Discontinuity, Gender Differences JEL Classification: D91, J24, Z29

*I am very grateful to my supervisors Lorenz Goette and Adrian Bruhin for their guidance and advice. I would like to thank John Antonakis, Bjoern Bartling, Nathan Carroll, Yan Chen, Roland Cheo, Lucas Coffman, Thomas Dohmen, Ruben Durante, Florian Englmaier, Simon Haenni, Holger Herz, Rafael Lalive, Friederike Mengel, Andreas Mueller, Luis Santos Pinto, Dominic Rohner, Adam Sanjurjo, Marie Claire Villeval, Roberto Weber, Chrisitan Zehnder, and participants in the applied micro coffee in Bonn, lab meeting and OB brownbag in Lausanne, IMEBESS 2016, ESA World Meeting 2016. A special thank to the Chinese regional swimming coach Qing Ji and the World University Champion Sifan Guo for comprehensive interviews.

†Author's Contact: University of Essex, Department of Economics, Wivenhoe Park, UK; Email: lingqing.jiang@essex.ac.uk 


\section{Introduction}

Peer effects can influence behaviors, decisions and outcomes in many contexts including educational outcomes (Hoxby 2000; Sacerdote 2001; Cipollone and Rosolia 2007; Lalive and Cattaneo 2009), productivity at work (Mas and Moretti 2009; Bandiera, Barankay and Rasul 2010), retirement planning (Duflo and Saez 2002; Beshears et al. 2015), and engagement in social activities (Bruhin et al. 2015; Chen et al. 2010; Bond et al. 2012).

A prevalent interpretation of peer effects is that individual behavior is influenced by a peer group's behavior and vice versa in a simultaneous setup. This corresponds to the endogenous social effects in Manski (1993). Manski also defined the exogenous social effects (or "contextual effects"), under which individual behavior is influenced by a peer group's fixed characteristics. The more recent peer effects literature thus distinguishes between endogenous peer effects and exogenous peer effects (e.g. Beugnot et al. (2013)).

On the one hand, studies using observational data to identify endogenous peer effects typically suffer from the reflection problem (Manski 1993). Lab experiments could utilise random assignment of subjects into different peer groups to identify causal effects but lack real social relationship among the subjects outside the lab. Field studies using subjects with existing social relationship mostly rely on natural experiments, field experiments, or instrumental variables as identification strategies (e.g. Cipollone and Rosolia (2007); Sacerdote (2001); Bruhin et al. (2015)). On the other hand, a handful of studies investigate exogenous peer effects by looking at some fixed composition of the peer group, for example, the gender ratio in the classroom (Lavy and Schlosser 2011), the proportion of low-ability students from earlier stage (Lavy, Paserman and Schlosser 2011), the concentration of immigrants (Gould, Lavy and Paserman 2009) and the presence of black students in the school on academic performance (Angrist and Lang 2004).

While a large body of the peer effects literature focuses on educational outcomes, an increasing number of studies are interested in how (endogenous and/or exogenous) peer effects operate on outcomes in the workplace (see a review of Herbst and Mas (2015)). Just to name a few, Falk and Ichino (2006) reported that the presence of another individual in- 
creases the focal individual's productivity in stuffing letters, using working alone as baseline in a lab experiment; In real working environment, Mas and Moretti (2009) showed that staff are more productive in scanning barcodes in grocery stores when facing a highly productive co-worker; Bandiera, Barankay and Rasul (2010) found that workers are more productive in picking soft fruit when a friend is working in the same field. Most of these studies were conducted among low-skilled individuals under the fixed payment scheme, but little is known about any sort of peer effects among high-skilled individuals under the tournament payment scheme involving high stakes. The latter is an especially important environment for peer effects as structural change is shifting the labor force toward high-skill sectors that are highly rewarding and often use tournaments for promotions (Lazear and Rosen 1981).

This paper contributes to the literature on exogenous peer effects in the context of highstakes tournaments. I investigate the effects of a peer group's composition on individual behavior by comparing individual performance in a group with a teammate with individual performance in a group without a teammate. ${ }^{1}$ When high-stakes rewards are mutually exclusive among peers, whether peer effects still imply positive externalities like under the fixed payment scheme remains unknown. An obvious candidate for such an environment is elite sports. ${ }^{2}$ In particular, I look at swimming tournaments as they have several desirable features. First of all, swimming, as an individual sport, does not require team cooperation, nor does it involve direct interaction with other competitors. This allows isolating peer effects per se, which are not confounded by complementarities in productivity. Secondly, the performance measures in swimming tournaments are precise, objective and standardized. Thirdly, swimming tournaments take place in highly controlled environments and the con-

\footnotetext{
${ }^{1}$ Besides the distinction between endogenous and exogenous peer effects, there is an ongoing discussion about the definition of peer groups, see for example in Halliday and Kwak (2012): "An informal sampling of the literature in educational peer effects shows the frequent use of school-grade cohorts as the peer group of interest. However, it is unclear whether school-grade cohorts are the true peer group in operation or whether they merely influence the composition of closer friendship ties, which in turn affect peer outcomes." If peer is narrowly defined as a socially connected person, the presence of a teammate is simply the presence of a peer per se. If peer is broadly defined, the presence of a teammate is a matter of the peer group's composition. Following the majority of the literature that uses a broad definition of peers, I interpret the presence of a teammate as a compositional characteristic of the peer group. These would be exogenous peer effects as the peer group's composition does not respond to focal individual's behavior in a simultaneous setup.

${ }^{2}$ See a review of research applying sports data to understand behavior and decision making by Balafoutas, Chowdhury and Plessner (2019).
} 
ditions such as timing, location and prize money, are the same for females and males, which allows a relatively fair comparison across gender compared to other sports. ${ }^{3}$

I use data from seven FINA (Fédération Internationale de Natation) World Swimming Championships which took place bi-annually between 2003 and 2015. ${ }^{4}$ I collected two samples consisting of 91 same-sex individual tournaments from the female and the male championships, respectively. Each individual tournament consists of three stages: multiple preliminary heats, two semifinal heats and a final heat. A heat is swum by eight athletes. FINA regulates that every national federation can qualify a maximum of two athletes for the preliminary heats of each individual tournament. ${ }^{5}$ The outcome of interest is athletes' performance in the finals of the tournaments, which means only the finalists are the focal athletes.

Given that sixteen athletes can qualify for the semifinals and eight athletes can qualify for the finals, some of the finalists lose their teammate during the course of the tournaments. I test whether finalists' performance is affected by the variation in the presence of their teammate in the same finals of the tournaments. Although athletes at the elite level may have an individual training team, there are several reasons for having strong social ties with other athletes in the same national team. First, they see each other frequently in national competitions. Second, they represent the same national federation in international competitions. Third, they may participate in the relay which requires training together. ${ }^{6}$ If athletes are solely motivated by intrinsic passion, prize money and fame, their performance is in-

\footnotetext{
${ }^{3}$ One may also consider other sports with similar features such as track and field and speed skating. However, swimming tournaments are preferable as the qualifications rules are more consistent over time than track and field tournaments, and athletes are much less vulnerable to strategic interruption by other competitors than speed skating tournaments. Therefore, the setup in swimming competition is more closer to the 'working environment' in the lab or field studied in the previous literature.

${ }^{4}$ These are the long course championships (50-meter pool) which is regarded as one of the most prestigious events in swimming. One may also consider other swimming events such as the Olympics, Short Course Championships, and World Cup. The long course championships occur more frequently than the Olympics and are more representative than other events.

${ }^{5}$ There are two qualifying entries, i.e. the B entry for qualifying one athlete and the A entry for qualifying both of two athletes from the same national federation. In order to analyse peer effects, I focus on national federations qualifying exactly two athletes.

${ }^{6}$ There are three relay disciplines: $4 \times 100 \mathrm{~m}$ Freestyle, $4 \times 200 \mathrm{~m}$ Freestyle, and $4 \times 100 \mathrm{~m}$ Medley. The Freestyle disciplines require four athletes in Freestyle while the Medley disciplines require one athlete in each style (Backstroke, Breaststroke, Butterfly, and Freestyle). Athletes who qualify for the individual disciplines are (non randomly) selected by the coach to participate in some of the relay disciplines.
} 
dependent of teammate's presence. However, if athletes are exposed to peer effects, and in particular the composition of the peer group, teammate's presence may have an influence on their performance. Whether this negatively or positively affects the performance is unclear under the tournament scheme.

The identification challenge lies in that the composition of the peer group is endogenous. This is one of the major identification problems that many observational studies face (Manski 1993, Moffit 2001). Athletes from the same national team have much in common. Most importantly, in this context, they have similar access to the facilities, coaching, supply of nutrition and even doping. Consequently, there is a substantial correlation between the performances of athletes from the same national team, especially from the traditional supremacies. In other words, athletes from strong teams are not only more likely to qualify themselves but are also more likely to have a teammate qualified for the same finals of the tournaments. A naive estimate of the effect based on the correlation might be upward biased.

In order to identify causal effects, I apply the concept of regression discontinuity design (RDD) which has become one of the most widely used quasi-experimental identification strategies (Hahn, Todd and Van der Klaauw 2001). I compare focal athletes' performance in the finals in two scenarios, i.e. when their teammate (i) barely qualified, and (ii) barely not qualified for the same finals. While athletes' semifinal performance is continuously distributed, the variation in their presence in the finals comes from the discontinuous jumps in the qualification status at the cutoff, which is predetermined as being ranked top eight among the sixteen semifinalists. There appears to be no reason, other than the teammate qualifying for the finals, for focal athletes' performance in the finals to be a discontinuous function of the teammate's performance in the semifinals. Therefore, one can attribute the discontinuous jump in focal athletes' performance in the finals at the qualification cutoff to the causal effect of the teammate's presence in the finals. ${ }^{7}$ Despite the fact that the cutoff is common knowledge, the qualification status of the teammate can be regarded as being quasi-

\footnotetext{
${ }^{7}$ One might interpret this effect as the difference between athletes' performance in the finals when their teammate did well and when their teammate did not so well in the semifinals. However, the distinction between the two interpretations lies in "barely". Since the teammate barely qualified for the finals, it is rather the qualification than the performance of the teammate that matters here.
} 
randomized within a narrow window around the cutoff. I constructed two windows based on the time and the rank, respectively. The time window takes a quarter of a standard deviation of the semifinal-time above and below the cutoff as the boundaries. The rank window takes two semifinal-ranks above and below the cutoff as the boundaries. ${ }^{8}$

Previous literature has documented gender differences in confidence and attitudes towards competition (see a survey in Niederle and Vesterlund (2011)). The peer effects studied in this paper may interact with athlete's confidence and attitudes towards competition and thus can be gender specific too. Therefore, I estimate the peer effects in the female and male sample respectively instead of pooling the two samples. In line with the findings in Yamane and Hayashi (2011), the baseline results show that female finalists accompanied by a teammate swam $0.45 \%-0.60 \%$ of the average time faster, or performed 0.80 to 1.18 (out of 8) ranks better than those who compete without a teammate. ${ }^{9}$ The performance of male finalists, however, does not seem to be affected by having a teammate accompanied. ${ }^{10}$

As a first placebo check, I look at the reduced forms with the real cutoff at the 8th rank and two placebo cutoffs, the 6th rank and the 10th rank, fixing the same window size. The reduced form coefficient of a teammate's presence is only significant at the real cutoff at which the variation in the qualification status actually occurs. As a second placebo check, I regress focal athletes' semifinal performance on a teammate's presence in the final within the same window. The presence of a teammate in the final should not have any impact on the focal athletes' performance in the semifinal as it could not be predicted beforehand. The results confirm this.

I also investigate the heterogeneity in the main effects in the following dimensions: age, experience, semifinal ranking and the individualism score of the athlete's country. While I find weak evidence that the effects of having a teammate are stronger for younger athletes and athletes from less individualistic countries in the female sample, I find no evidence that

\footnotetext{
${ }^{8}$ The size of the windows was suggested by an elite level swimming coach, Qing Ji.

${ }^{9}$ This means, for example, in a race of which the average time is 50 seconds, the effect is $0.60 \% \times 50=$ 0.3 seconds.

${ }^{10}$ It is important to notice that these results are not driven by construction, e.g. if the 7th or the 8th-place is filled by a teammate, it increases the rank of the focal athlete since the focal athlete can not take the 7 th or the 8th-place. The 7th or the 8th-place always has to be filled by an athlete, be it the teammate or a foreign athlete.
} 
the main effects vary with the experience or the semifinal ranking in either sample.

Finally, I discuss two potential mechanisms that may autonomously or jointly drive the main effects observed. First, having a teammate may enhance intra-team competition as the teammate is the only national competitor that is relevant for sponsorship and other economic sources at the national level. I find no evidence that the observed peer effects are stronger when the teammates are close competitors. This, however, does not rule out that the intrateam competition can be switched on simply by the existence of a teammate regardless the relative ability of the teammate. Second, having a teammate may mitigate the psychosocial pressure. Athletes in elite level tournaments are under enormous pressure which prevents them from reaching the optimal performance. The psychosocial pressure could be mitigated by, for example: i) not representing the country alone; ii) receiving motivational support from the teammate.

This study contributes to the literature on peer effects in the workplace. As mentioned before, Falk and Ichino (2006), Mas and Moretti (2009) and Bandiera, Barankay and Rasul (2010) found positive peer effects among low-skilled subjects who receive fixed low-stakes payments. ${ }^{11}$ Graff, Grund and Harbring (2018) found effects of virtual peers on performance in virtual reality tournaments. On the other hand, Guryan, Kroft and Notowidigdo (2009) and Carroll (2012) did not find peer effects on the performance of professional golf players. Guryan, Kroft and Notowidigdo (2009) speculated that the professional experience and competitive environments can mitigate peer effects. ${ }^{12}$

Yamane and Hayashi (2011) and Yamane and Hayashi (2015) also studied peer effects in swimming competitions. It is therefore important to notice the differences between their papers and the current one. The most important differences between the work of Yamane and Hayashi (2011, 2015) and my paper are summarized as follows: 1) Subjects: the former uses mostly elementary and junior high school students and the latter uses professional athletes;

\footnotetext{
${ }^{11}$ Van Veldhuizen, Oosterbeek and Sonnemans (2018) studied the role of observability for peer effects in a similar setup as Mas and Moretti (2009) in the lab. However, they did not find evidence for the same pattern of peer effects as Mas and Moretti (2009) in the field.

${ }^{12}$ Kießling, Radbruch and Schaube (2018) provides additional evidence in a different sport that is in line with my findings. In a field experiment, they found that subjects perform better in the running tasks when they are paired with a known individual than a randomly assigned individual, and the difference is not explained by the ability of the other individual.
} 
2) Peers: the former defines peers as competitors in adjacent lanes and the latter defines peers as the national teammate; 3) Incentives: the former offers no monetary incentives and the latter involves high-stakes monetary incentives; 4) Identification strategy: the former utilizes participant absenteeism and the latter applies a regression discontinuity design; 5) Findings regarding gender differences: the former finds that female participants' performance is more positively influenced than males by the existence of competitors in adjacent lanes and the latter finds that female athletes perform better with a teammate than without.

Given the contribution of Yamane and Hayashi's papers, the value added of my paper is that it investigates high-skilled subjects who are incentivized by high-stakes rewards. In many applications such as job promotions, patent races, and elections, tournament participants (e.g. candidates competing for promotions, firms competing for patents, politicians competing for votes) are professionals and the outcomes often involve very large stakes. It is well documented that large stakes can alter the perception of the tasks and the behavior (Slonim and Roth 1998; Ariely et al. 2009; Andersen et al. 2011). Therefore, it is important to verify whether the peer effects previously observed in low-stakes environment are invariant to high stakes. Last but not least, the peer in my study is not any person who happens to be nearby or in the same situation as the focal individuals but someone who is actually socially connected to the focal individuals. Although individuals can be influenced by either type of peers (strangers or socially connected individuals), the latter ones are more relevant when it comes to important decisions (e.g. friends in schooling decisions (Cipollone and Rosolia 2007), colleagues in retirement planning (Duflo and Saez 2002), neighbours in voting behavior (Gerber, Green and Larimer 2008).).

This study also complements the literature on gender differences in competitive environments. A large body of the literature on gender differences in competitions focuses on the preference for competition per se (e.g. Niederle and Vesterlund (2007); Garratt, Weinberger and Johnson (2013)); my study involves elite athletes of both genders who long ago made the choice to participate in a highly competitive environment. Other papers focus on the gender composition of the competitors (e.g. Gneezy and Rustichini (2004)); my study examines the effect of the presence or absence of a same-sex peer, rather than the gender composition of 
the peer group. Yamane and Hayashi (2011) found that females swim faster in the presence of a competitor while males do not. Chen, Ong and Sheremeta (2015) found females have a higher value of winning than males when bidding against females in all-pay auctions. The gender difference found in this paper are consistent with gender differences in responding to competitive or psychosocial pressure and in competitive environment (conditional on being in the competition).

While the setup of this study might be specific, it is a real competitive environment with high-stakes incentives. Hence, the essence of the results is of general interest as the society is undergoing structural change that shifts the labor force toward high-skill sectors that are highly rewarding and often use tournaments for recruitments or promotions. Even with high financial incentives, social incentives can still play an important role in motivating individuals to make higher effort.

In particular, in the context of job openings or promotions, organisations could take into account the potential peer effects and gender differences to design social incentives. My results suggest that female candidates perform better when the competing pool contains someone who is socially connected than someone less familiar. For example, when a promotion consists of both internal and external candidates, the internal candidates may have an extra motivation as they know each other. Similarly, on the job market, applicants who have a socially connected peer (let it be from the same university, same country or connected through other means) applying for similar jobs may also feel extra motivated. Taking into account the potential gender difference is especially important if firms would like to improve female-male ratio in the management team. The fact that there are not enough female labor force participants in the first place will make female applicants even less likely to have socially connected or similar peers in the same pool, which may further impair their motivation.

The remainder of the paper is organized as follows, Section 2 describes the data, Section 3 illustrates the identification problem and identification strategy, Section 4 presents the empirical analysis, Section 5 reports the main results, two placebo checks and the heterogeneity analysis, Section 6 discusses potential mechanisms, and Section 7 concludes. 


\section{Data}

I use data from seven FINA World Swimming Championships (long course) which took place bi-annually between 2003 and 2015. I collected two samples consisting of 91 samesex individual tournaments from the female and the male championships, respectively. Table 1 shows the number of finalists in each discipline included in the sample. ${ }^{13}$ Each tournament consists of three stages: multiple preliminary heats, two semifinal heats and a final heat. During the course of the tournament, sixteen athletes can qualify for the semifinal and eight athletes can qualify for the final. Individual performances in each stage of the tournaments and the personal characteristics including age, gender and nationality are collected from the FINA homepage (http://www.fina.org). The outcome of interest is athletes' performance in the final stage of the tournaments, which means only the finalists are the focal athletes.

Table 1: Number of finalists in each discipline

\begin{tabular}{|c|c|c|c|c|c|c|}
\hline & & Female & & & Male & \\
\hline Stroke & $50 \mathrm{~m}$ & $100 \mathrm{~m}$ & $200 \mathrm{~m}$ & $50 \mathrm{~m}$ & $100 \mathrm{~m}$ & $200 \mathrm{~m}$ \\
\hline Backstroke & 56 & 56 & 56 & 56 & 56 & 56 \\
\hline Breaststroke & 55 & 56 & 56 & 55 & 56 & 56 \\
\hline Butterfly & 56 & 56 & 56 & 56 & 56 & 56 \\
\hline Freestyle & 56 & 56 & 56 & 56 & 56 & 56 \\
\hline Individual Medley & - & - & 56 & - & - & 56 \\
\hline Total & 223 & 224 & 280 & 223 & 224 & 280 \\
\hline
\end{tabular}

A key feature of the FINA World Swimming Championship is that every national federation can qualify a maximum of two athletes for the preliminary heats of each individual tournament. The qualifying standard depends on the number of athletes a national federation wants to qualify. To qualify a single athlete, one only needs to meet the B entry. To qualify two athletes, both of the athletes need to meet the A entry which is slightly higher

\footnotetext{
${ }^{13}$ For the analysis I focus only on short-distance disciplines (up to 200 meters) for three reasons: i) only Freestyle and Individual Medley have disciplines in longer distances, and they do not have semifinals; ii) long-distance disciplines involve more complex strategies, and conserving energy in the preliminary heats and semifinals is more likely to occur in long-distance disciplines; iii) my identification strategy which uses a regression discontinuity design is most suitable for the highly competitive disciplines in short distances. It requires imperfect control over the qualification status, and I will make this clear in Section 3.3.
} 
than the B entry. ${ }^{14}$ To study the effects of having a teammate in the finals, I naturally only focus on athletes that qualify together with their teammate.

Table 2: Tournament finalists descriptive statistics

\begin{tabular}{lcc}
\hline & Mean & Std. Dev. \\
\hline Female & & \\
\hline Age & 22.24 & 3.59 \\
Share of finalists with a teammate in the semifinal & $57.08 \%$ & \\
Share of finalists with a teammate in the final & $36.86 \%$ & \\
Number of individual observations in the final & 727 & \\
\hline \hline Male & & \\
\hline Age & 24.02 & 3.36 \\
Share of finalists with a teammate in the semifinal & $52.27 \%$ & \\
Share of finalists with a teammate in the final & $30.54 \%$ & \\
Number of individual observations & 727 & \\
\hline
\end{tabular}

Table 2 provides the descriptive statistics of the finalists in all the tournaments. Female finalists are on average $22.24(\operatorname{std}=3.59)$ years old and male finalists are on average 24.02 ( $\mathrm{std}=3.36$ ) years old. Among the 727 female observations, $57.08 \%$ of them have a teammate in the semifinals and $36.86 \%$ of them have a teammate in the finals. Among the 727 male observations, $52.27 \%$ of them have a teammate in the semifinals and $30.54 \%$ of them have a teammate in the finals.

Table 3: An example of the hybrid of within- and between-subject design

\begin{tabular}{ccc}
\hline Finalist & National Team & Tournament \\
\hline PHELPS & USA & Men's 200m Freestyle (2009) \\
$\emptyset$ & USA & \\
\hline PHELPS & USA & Men's 200m Freestyle (2011) \\
LOCHTE & USA & \\
\hline PHELPS & USA & Men's 100m Butterfly (2011) \\
MCGILL & USA & \\
\hline FUJII & JPN & Men's 100m Butterfly (2011) \\
$\emptyset$ & JPN & \\
\hline
\end{tabular}

\footnotetext{
${ }^{14}$ According to FINA's official selection criteria, there are two entry time standards: A Time Standard/Entry and B Time Standard/Entry. "A maximum of two swimmers can be entered per event provided both swimmers meet the A Time Standard. One Swimmer can qualify with a B Time Standard provided no swimmers achieve the A time standard in that event and they are the fastest B Time Standard." The A Time Standard is faster than the B Time Standard. The exact standard of each entry varies across disciplines, years, and meetings.
} 
Table 3 illustrates several characteristics worth noting in this sample. First, the composition of the national team is not necessarily fixed. This comes from two dimensions. The first is the discipline dimension, e.g. Phelps and Lochte in the Men's 200m Freestyle (2011) was one dyad, whereas Phelps and McGill in the Men's 100m Butterfly (2011) was another dyad. The second is the time dimension. Athletes reach their performance peak at different points in time and have their career of different length, thus, athletes may have different teammates throughout their career. Second, this is a hybrid of within- and between-subject design. The answer to the research question comes from the comparison of athletes' performance when their teammate is present and when their teammate is absent in the same finals. On the one hand, in the top three rows of Table 3, it shows a within-subject comparison when one compares the performance of Phelps in the Men's 200m Freestyle (2009) with his performance in the Men's 200m Freestyle (2011) and Men's 100m Butterfly (2011). The former case is without a teammate and the latter two cases are with a teammate; On the other hand, in the bottom three rows of Table 3, it shows a between-subject comparison when one compares the performance of Phelps in the Men's 200m Freestyle (2011) and Men's 100m Butterfly (2011) with the performance of Fujii in the Men's 100m Butterfly (2011). The former two cases are with a teammate and the latter case is without a teammate.

Figure 1 gives an overview of the average performance in the finals of each discipline. The upper scatters are the 200-meter, the middle scatters are the 100-meter and the bottom scatters are the 50-meter disciplines. The performances vary across different strokes and gender, with time increasing in the distance. Very roughly speaking, it takes about 25 seconds to finish a 50-meter final, one minute to finish a 100-meter final and two minutes to finish a 200-meter final. The performance is standardised and precisely recorded by the official timekeeper.

Finally, elite level tournaments involve high stakes. Besides the standard prize money, there are potential commercial contracts with hefty sums for outstanding athletes, and of course worldwide prestige. 


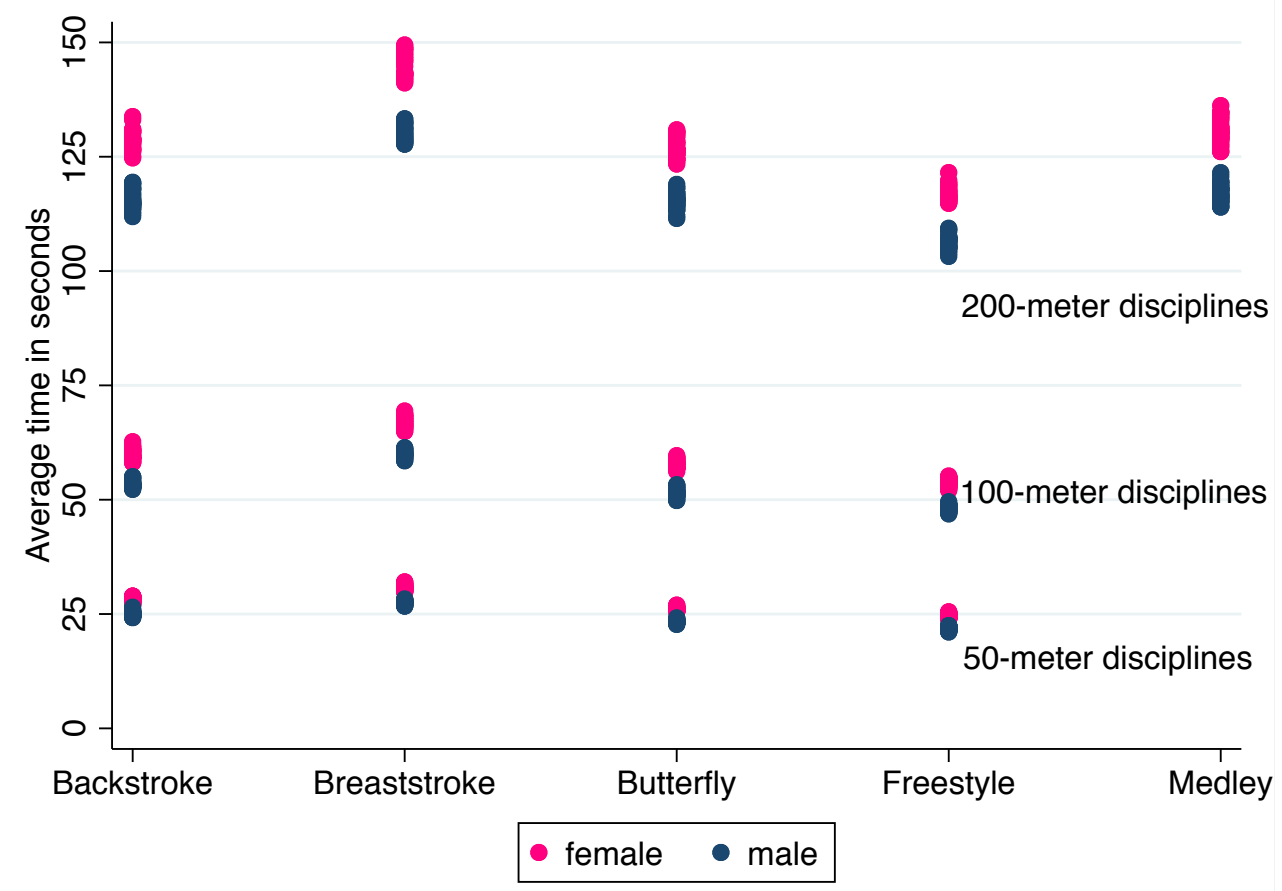

Note: The upper/ middle/ bottom scatters indicate the 200-meter/ 100-meter/ 50-meter disciplines. Notice that there are no 100-meter or 50-meter Medley disciplines.

Figure 1: Average time (in seconds) used in the finals, by discipline

\section{Identification of Peer Effects}

This section describes the identification challenges, illustrates the identification strategy and determines its key elements.

\subsection{Identification Challenges}

Unlike in a controlled experiment, having a teammate in the same finals is not randomized in this setup. First of all, as mentioned in Section 2, there are two qualifying time standards. The standard to qualify two athletes is higher than the one to quality one athlete for the tournaments. Therefore, by construction, only strong national teams can qualify in pairs for the tournaments. Moreover, athletes from the same national team share much in common. Most importantly, in this context, they have similar access to the facilities, coaching, supply of nutritions and even the doping technology. As a result, there is substantial correlation between the performance of athletes from the same national team, especially from the traditional supremacies. In other words, athletes from the very strong teams are not only more likely to 
advance to the finals themselves but are also more likely to have a teammate advancing to the same finals of the tournaments. Therefore, if one compares the final performance of two athletes from a national team with the performance of a single athlete from another national team, it will reflect the gap in the overall strength between strong and less strong national teams.

\subsection{Identification Strategy}

In order to overcome the obstacles above and identify causal effects, one needs to make the presence of a teammate "quasi-random" in the final stage of the tournaments. To do so, in the first step, I only focus on teams that qualify in pairs for the tournaments, i.e. each team has two athletes at the preliminary stage of the tournaments. This will ensure that all the athletes qualify through the same entry standard. As we are interested in the final performance, our focal athletes are all the finalists. In the second step, conditional on qualifying in pairs for the tournaments, I separate the focal athletes into two groups: a "control" group where focal athletes' teammate barely not qualified for the final stage, and a "treated" group where focal athletes' teammate barely qualified for the final stage. Notice that other athletes whose teammates either did not quality for the final or qualified outside the window are dropped from the study. Conceptually, I am applying a Regression Discontinuity Design (RDD). The RDD has become one of the most widely used quasi-experimental identification strategies (Hahn, Todd and Van der Klaauw 2001).

The key feature of the design is that while the performance of the athletes in the semifinals is continuously distributed, the probability of having a teammate in the same finals conditional on the teammate's semifinal performance jumps discontinuously at the qualification cutoff. This cutoff is predetermined as being ranked top eight among the sixteen athletes in the semifinals. Therefore, the variation in the treatment assignment can be assumed to be unrelated to potential confounders. ${ }^{15}$ Although the cutoff is public knowledge to all, athletes ranked barely above or below the cutoff in the semifinal have imperfect control over

\footnotetext{
${ }^{15} \mathrm{I}$ assume that there are no intertemporal effects that spill over from finals when a teammate is present to finals when a teammate is absent, and vice versa.
} 
their qualification status for the reasons that will be discussed in detail in Section 3.3 below. Thus, their presence in the finals can be regarded as quasi-random. In the terminology of $\mathrm{RDD}$, the running variable is the time, or the corresponding rank, of the teammate in the semifinals, and the treatment variable is the presence of the teammate in the finals. It is important to notice that being ranked above or at the cutoff does not necessarily mean being actually present in the finals due to the following reasons. First, if there are ties between or among the athletes ranked at the cutoff, i.e. two or more athletes are ranked at eight in the semifinals, these athletes need to swim again, which is called the Swim-off. Second, even if qualifying for the finals, one can still drop out (DNS) due to injury or failing to pass the doping test, for example. In such cases, the athletes on the reservation list, typically ranked at nine or ten, can fill the space. Therefore, this is a fuzzy RDD, in which the probability of the treatment jumps at the cutoff rather than being fully deterministic. The treatment variable is instrumented by an indicator of the teammate being ranked above or at the cutoff.

\subsection{The Window Size}

In this section I will determine the size of the window around the cutoff within which the qualification status of the athletes can be regarded as quasi-random. For illustration, let us first consider a Swim-off event where exactly two athletes ranked eight in the semifinal, and each of the two athletes involved in the Swim-off has a teammate who had already qualified for the final. The Swim-off perfectly demonstrates how one athlete barely qualifies and the other barely not. After an additional race, one qualifies and the other does not, and the focal athlete whose teammate won the Swim-off retains the dyad in the final whereas the other is left "alone" in the final. ${ }^{16}$

There are two questions the answers of which are crucial for determining the size of the window. First: if there is a window around the cutoff within which the athletes have little control over the qualification status, what are the main sources of the imperfect control?

The first source is the reaction time. Besides the total time, the timekeeper also records

\footnotetext{
${ }^{16}$ If necessary, multiple swim-offs can take place.
} 
the reaction time of each athlete, which is the time between the starting signal and the first movement of any kind after the signal. The reaction time depends on several aspects, e.g. how reactive the athlete is, how far the athlete is from the signal, and the intensity of the signal among other things. In the semifinals of this sample, female athletes' average reaction time is 0.73 seconds $(\min =0.49 ; \max =0.97)$ and male athletes' average reaction time is 0.71 seconds $(\min =0.42 ; \max =0.97)$. It is a nontrivial fraction of a race, especially in the short-distance tournaments where every fingernail counts.

Another source of imperfect control is the "time qualification", under which two heats are swum in the semifinals, and the semifinal ranking is determined by the time recorded in the heats. It is not the first four athletes in each heat who qualify for the final, but the first eight athletes in the semifinal qualify. Without seeing half of the athletes in the other heat, it is hard to predict the qualification status of each athlete, especially for those who are around the cutoff. ${ }^{17}$ For example, being ranked at three or four in one of the semifinal heats does not guarantee the qualification for the final. These two sources of uncertainty are clearly out of the perfect control of the athletes.

The second question is: in what time range around the cutoff can those sources of imperfect control operate? To answer this question, let us investigate the Swim-off again. The time difference between the athletes in the Swim-off tells us roughly to what extent "equally" competent athletes can differ if they race again. During the sample period, there were in total ten Swim-off events in the 50-meter disciplines, where the Swim-off took place most frequently. The average time difference is 0.17 seconds $(\min =0.01 ; \max =0.52)$. As we noticed in Figure 1, the time varies a lot across disciplines, therefore, one needs a benchmark for the time difference.

Given the facts listed above, and incorporating information learned from an interview with an elite level swimming coach, I determined a half of a standard deviation of the time used in the semifinal as the window size. Using standard deviations to approximate the time is advantageous as it takes into account the dispersion of athletes' performances. A half

\footnotetext{
${ }^{17}$ Given that there are only a few minutes between the heats and that athletes in the call room typically isolate themselves from outside before their own race, athletes seeded in different heats do not observe each other.
} 


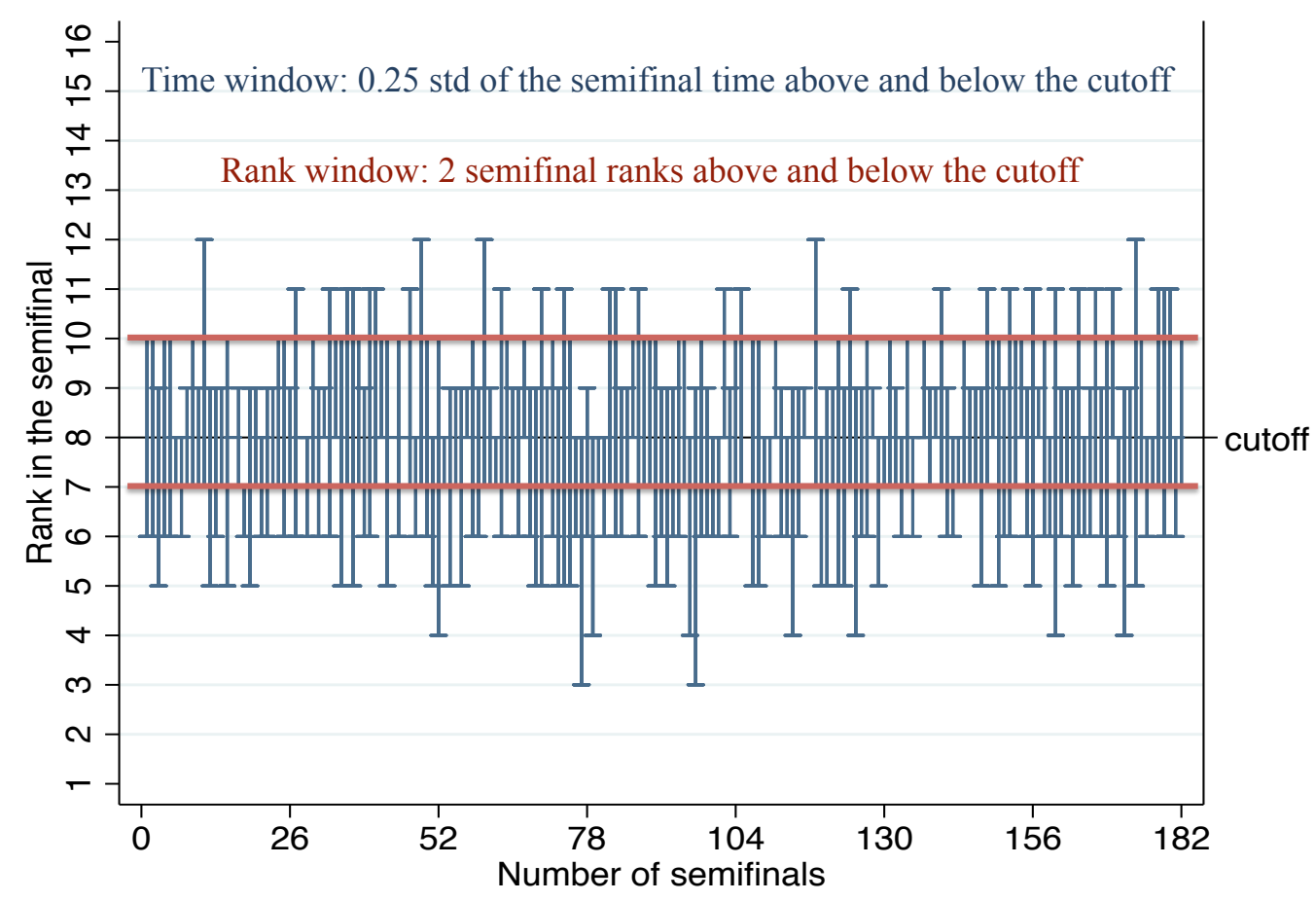

Note: The blue vertical intervals indicate the time window which is tailored for each tournament.

The red horizontal intervals indicate the rank window which is uniform for each tournament.

Figure 2: Time and rank window

of a standard deviation would approximately corresponds to 0.1 seconds in the Men's $50 \mathrm{~m}$ Freestyle, for example. Within a 0.1 -second difference, the rank can easily be reversed by a shorter or longer reaction time in the semifinals, and it is also approximately the same magnitude of the time difference in most Swim-off events. Hence, I construct the time window with a quarter of one standard deviation of the time at or above, and below the cutoff time for all the 182 semifinals in both the female and the male sample. Notice that this tailors the size of time window for each tournament. Alternatively, I construct a rank window using a uniform range of ranks, i.e. two ranks at or above, and below the cutoff.

Figure 2 illustrates both the time window (in blue) and the rank window (in red). Notice that both windows are expressed in rank units. In the time window, each of the blue vertical intervals indicates the rank units corresponding to a quarter of a standard deviation of the time used in the semifinal at or above, and below the cutoff in each tournament. For instance, in the first tournament, a half of standard deviation of the time spans the rank 6 to 10 ; in the last tournament, a half of standard deviation of the time spans the rank 7 to 10 . As can be 
seen in the figure, the two windows contain different sets of observations. However, they result in almost the same number of observations. ${ }^{18}$

\section{Empirical Analysis}

This section first performs a balance check of the covariates of the athletes whose teammate was barely above and below the qualification cutoff, and then presents the econometric model.

\subsection{Balance Check of Covariates}

I check whether the characteristics of the focal athletes are comparable when their teammate was barely above and below the cutoff using a two sample Wilcoxon rank-sum (MannWhitney U) test. ${ }^{19}$ The results using the rank window are reported in Table $4 .{ }^{20}$ Conditional on having a teammate in the semifinal, the first column reports the median characteristics of the finalists whose teammate ranked barely below the cutoff (semifinal rank 9 or 10), and the second column reports the median characteristics of finalists whose teammate ranked barely above the cutoff (semifinal rank 7 or 8). The characteristics include age, the number of finals qualified in a single championship (Champ.) as well as during the whole sample period (Total), and the normalized time in the semifinal. Table 4 shows that finalists whose teammate is ranked 9 th or 10th in the semifinals have no significantly different characteristics from finalists whose teammate is ranked 7th or 8th in the semifinals in both samples.

\footnotetext{
${ }^{18}$ A dyad may be used twice only if both athletes are barely at or above the cutoff, i.e. both are focal athletes with a teammate barely qualified. Actually, only three dyads fulfill this requirement in the sample. In these cases, dropping a randomly selected second observation of the same dyad does not change the results. Further more, the placebo check 1 rules out that the effects are driven by such "well-matched" pairs, because otherwise we would have observed some pseudo effects at other placebo cutoffs.

${ }^{19}$ The Wilcoxon rank-sum test does not assume normal distribution of the variables and is more efficient and robust than the t-test.

${ }^{20}$ The test results using the time window are very similar and can be found in Table A8 in the Appendix.
} 
Table 4: Characteristics of finalists, by teammate rank

\begin{tabular}{lccc}
\hline & $(1)$ & $(2)$ & $(3)$ \\
Median of Covariates & $\begin{array}{c}\text { Teammate's semifinal } \\
\text { rank } \in\{9,10\}\end{array}$ & $\begin{array}{c}\text { Teammate's semifinal } \\
\text { rank } \in\{7,8\}\end{array}$ & $\begin{array}{c}\text { Wilcoxon rank-sum test } \\
\text { p-value }\end{array}$ \\
\hline \hline Panel A: Female sample & & & \\
\hline Age & & & 0.80 \\
No. Finals (Champ.) & 22 & 1.5 & 0.55 \\
No. Finals (Total) & 2 & 2 & 0.74 \\
Normalized time (SF) & 3 & 0.991 & 0.37 \\
Total & 0.992 & 52 & \\
\hline \hline & 43 & & 0.94 \\
Panel B: Male sample & & & 0.52 \\
\hline Age & & 24 & 0.19 \\
No. Finals (Champ.) & 1 & 1 & 0.99 \\
No. Finals (Total) & 3 & 2 & \\
Normalized time (SF) & 0.992 & 0.992 & \\
Total & 47 & 46 & \\
\hline
\end{tabular}

\subsection{The Econometric Model}

In the econometric model, Equation 4.1, I regress finalist $i$ 's performance in tournament $t$ on a dummy variable indicating whether her teammate $j$ is present in the same final, controlling for $i$ 's and $j$ 's age, $i$ 's ability, and the ability heterogeneity in tournament $t .{ }^{21}$ Controlling for the ability heterogeneity is important as all athletes' performance in each stage is public knowledge which can affect their final performance (Sunde 2009; Graff, Grund and Harbring 2018). Three sets of fixed effects are included in the regressions. The discipline fixed effects take care of the differences across the strokes and distances. The championship fixed effects account for the differences across years and locations. Finally, the finalist's country fixed effects control for the differences in the overall strength across countries.

Performance $_{i, t}=\delta$ Teammate $_{i, t}+\beta_{1}$ Age $_{i, t}+\beta_{2}$ Age $_{j, t}+\beta_{3}$ Ability $_{i, t}+\beta_{4}$ AbilityHet $_{t}+\epsilon_{i, t}$

The official performance is recorded in raw time. In order to pool all the tournaments

\footnotetext{
${ }^{21}$ The inclusion of control variables in the model is to increase precision and remove biases even though the setup can be seen as an quasi-randomized experiment. According to Athey and Imbens (2017), there are two principal roles of covariates in (completely) randomized experiments: "First, incorporating covariates may make analyses more informative. Second, even if the original randomization was done appropriately, adjusting for covariate differences may remove biases."
} 
together, I use i) the normalized time and ii) the rank as performance measures. ${ }^{22}$ The time is normalized by taking the ratio of the own time in the final over the average time of the sixteen athletes in the semifinal, and multiplied by 100 . The ability is approximated by the own normalized time in the semifinal, and multiplied by -100 . The ability heterogeneity is measured as the coefficient of variation of the eight finalists' time in the semifinal, and multiplied by $100 .{ }^{23}$

The variable of interest is the teammate dummy. Since I apply a fuzzy RDD, this variable is instrumented by the indicator of being ranked above or at the qualification cutoff in the first stage of the two-stage least squares (TSLS) estimation (Angrist and Pischke 2008). The main coefficient of interest is $\delta$, which captures the average treatment effect of having a teammate in the same final on $i$ 's performance.

\section{Results}

This section presents the baseline results of the estimated peer effects, two placebo checks, and the analysis of effect heterogeneity.

\subsection{Baseline Results}

Table 5 reports the TSLS estimates of the performance effect of having a teammate in the same finals. Panel A and Panel B present the results in the female and male sample, respectively. ${ }^{24}$ Columns (1) and (2) use normalized time and columns (3) and (4) use rank as the outcome variables. Columns (1) and (3) use the time window and columns (2) and (4) use the rank window within which the variation in the teammate's presence in the same finals is quasi-random. Notice that a negative coefficient corresponds to a positive effect on

\footnotetext{
${ }^{22}$ Notice that one can improve in time but may not always be able to improve in rank because there is a ceiling in the rank measure.

${ }^{23}$ One could also use the qualifying time as an ability measure, however, the qualifying time is achieved during the qualifying period which is more than one year before the current championship. The same holds for the personal best time. Therefore, the time in the semifinal of the current championship is a better measure of current ability.

${ }^{24}$ Since the key regressor - the teammate dummy - is as good as randomly assigned within individual clusters, there is no need to cluster standard errors (Cameron and Miller 2015). The results with standard errors clustered at the individual level are very similar and can be found in Table A10 in the Appendix.
} 
Table 5: Two-stage least squares estimates of the effect of having a teammate in the same finals on the final performance

\begin{tabular}{|c|c|c|c|c|}
\hline \multicolumn{5}{|l|}{ Panel A: Female } \\
\hline VARIABLES & $\begin{array}{c}(1) \\
\text { Time }\end{array}$ & $\begin{array}{c}(2) \\
\text { Time }\end{array}$ & $\begin{array}{c}(3) \\
\text { Rank }\end{array}$ & $\begin{array}{c}(4) \\
\text { Rank }\end{array}$ \\
\hline Teammate (F) & $\begin{array}{c}-0.602 * * * \\
(0.207)\end{array}$ & $\begin{array}{c}-0.448 * * * \\
(0.161)\end{array}$ & $\begin{array}{c}-1.187 * * * \\
(0.429)\end{array}$ & $\begin{array}{c}-0.796 * * \\
(0.334)\end{array}$ \\
\hline Age & $\begin{array}{l}0.00261 \\
(0.0339)\end{array}$ & $\begin{array}{l}-0.0416 \\
(0.0372)\end{array}$ & $\begin{array}{l}-0.0169 \\
(0.0588)\end{array}$ & $\begin{array}{l}-0.0953 \\
(0.0622)\end{array}$ \\
\hline Teammate's age & $\begin{array}{c}-0.00670 \\
(0.0240)\end{array}$ & $\begin{array}{l}-0.00185 \\
(0.0220)\end{array}$ & $\begin{array}{l}0.00447 \\
(0.0616)\end{array}$ & $\begin{array}{c}-0.000181 \\
(0.0436)\end{array}$ \\
\hline Ability & $\begin{array}{c}-0.949 * * * \\
(0.134)\end{array}$ & $\begin{array}{c}-1.117 * * * \\
(0.139)\end{array}$ & $\begin{array}{c}-1.739 * * * \\
(0.252)\end{array}$ & $\begin{array}{c}-2.116 * * * \\
(0.268)\end{array}$ \\
\hline Ability Heterogeneity & $\begin{array}{l}-0.447 \\
(0.601)\end{array}$ & $\begin{array}{l}-0.569 \\
(0.573)\end{array}$ & $\begin{array}{l}-0.328 \\
(0.985)\end{array}$ & $\begin{array}{l}-0.575 \\
(0.925)\end{array}$ \\
\hline $\begin{array}{l}{[-0.25,+0.25] \text { Std }} \\
{[-2,+2] \text { Ranks }}\end{array}$ & yes & yes & yes & yes \\
\hline Discipline FEs & yes & yes & yes & yes \\
\hline Championship FEs & yes & yes & yes & yes \\
\hline Country FEs & yes & yes & yes & yes \\
\hline F-statistics of Instrument & 518.686 & 534.205 & 518.686 & 534.205 \\
\hline Observations & 97 & 95 & 97 & 95 \\
\hline R-squared & 0.457 & 0.481 & 0.389 & 0.457 \\
\hline
\end{tabular}

Panel B: Male

\begin{tabular}{|c|c|c|c|c|}
\hline VARIABLES & Time & Time & Rank & Rank \\
\hline \multirow[t]{2}{*}{ Teammate $(\mathrm{F})$} & 0.0596 & 0.00508 & 0.236 & 0.295 \\
\hline & $(0.160)$ & $(0.153)$ & $(0.360)$ & $(0.345)$ \\
\hline \multirow[t]{2}{*}{ Age } & 0.0208 & 0.0269 & 0.00493 & 0.00919 \\
\hline & $(0.0172)$ & $(0.0207)$ & $(0.0370)$ & $(0.0505)$ \\
\hline \multirow[t]{2}{*}{ Teammate's age } & 0.0133 & 0.00408 & 0.0193 & 0.0205 \\
\hline & $(0.0212)$ & $(0.0274)$ & $(0.0478)$ & $(0.0634)$ \\
\hline \multirow[t]{2}{*}{ Ability } & $-1.273 * * *$ & $-1.224 * * *$ & $-2.800 * * *$ & $-2.595 * * *$ \\
\hline & $(0.128)$ & $(0.121)$ & $(0.253)$ & $(0.259)$ \\
\hline \multirow[t]{2}{*}{ Ability Heterogeneity } & $0.795^{*}$ & $0.780^{*}$ & $2.144 * *$ & $1.927 * *$ \\
\hline & $(0.442)$ & $(0.432)$ & $(0.918)$ & $(0.913)$ \\
\hline \multirow{2}{*}{$\begin{array}{l}{[-0.25,+0.25] \text { Std }} \\
{[-2,+2] \text { Ranks }}\end{array}$} & \multirow[t]{2}{*}{ yes } & \multicolumn{3}{|c|}{ yes } \\
\hline & & \multicolumn{2}{|l|}{ yes } & yes \\
\hline \multirow{3}{*}{$\begin{array}{l}\text { Discipline FEs } \\
\text { Championship FEs } \\
\text { Country FEs }\end{array}$} & yes & yes & yes & yes \\
\hline & yes & yes & yes & yes \\
\hline & yes & yes & yes & yes \\
\hline F-statistics of Instrument & 691.607 & 771.212 & 691.607 & 771.212 \\
\hline Observations & 90 & 93 & 90 & 93 \\
\hline R-squared & 0.671 & 0.618 & 0.660 & 0.599 \\
\hline \multirow{2}{*}{\multicolumn{5}{|c|}{$\begin{array}{l}\text { Notes: Robust standard errors in parentheses. }{ }^{* * *} \mathrm{p}<0.01, * * \mathrm{p}<0.05, * \mathrm{p}<0.1 \\
\text { Normalized time is the ratio of the own time in the final over the average time } \\
\text { of the sixteen athletes in the semifinal, and multiplied by } 100 \text {. }\end{array}$}} \\
\hline & & & & \\
\hline \multicolumn{5}{|c|}{$\begin{array}{l}\text { The ability is normalized time in the semifinal over the average time in preliminary } \\
\text { heats and multiplied by }-100 \text {. }\end{array}$} \\
\hline \multicolumn{5}{|c|}{$\begin{array}{l}\text { The ability heterogeneity is measured as the coefficient of variation of the eight } \\
\text { finalists' time in the semifinal, and multiplied by } 100 .\end{array}$} \\
\hline
\end{tabular}


performance, as the shorter the time, or the higher the rank, the better the performance. ${ }^{25}$ In Panel A, the coefficients of the teammate dummy are 0.60 and 0.45 in columns (1) and (2), respectively. Since the normalized time is divided by the average time in the semifinal, this means that female athletes accompanied by a teammate swam $0.45 \%-0.60 \%$ of the average time faster. To see the magnitude of this effect, consider an average time of 50 seconds in the semifinal, then the effect would be $0.60 \% \times 50=0.3$ seconds faster. The coefficients in columns (3) and (4) show that female athletes accompanied by a teammate perform 1.18 to 0.80 ranks better. Recall that the rank spans from one to eight in the final heat. The effects are smaller with the rank window than with the time window for both outcomes, but they are not statistically different. In all the columns in Panel B, the coefficients of the teammate dummy are insignificant, much smaller in magnitude, and have the opposite sign compared to the female sample. The performance of male athletes does not seem to be affected by the presence of a teammate. After controlling for current ability, neither the own age nor the teammate's age has a significant effect on the performance in the finals in both the female and the male sample. Semifinal performance is highly and positively correlated with the final performance in both samples. The ability heterogeneity seems to be uncorrelated with female athletes' performance but negatively correlated with male athletes' performance. The latter is in line with the empirical evidence testing tournament theory (e.g. Sunde (2009); Graff, Grund and Harbring (2018)). ${ }^{26}$

I also perform the same analysis in the semifinals, i.e. whether having a teammate in the same semifinals affects the semifinal performance. Notice that athletes winning the semifinals does not receive any sort of financial rewards. Not surprisingly, the effects of having a teammate are insignificant in the semifinals where the championship is not yet at stake. Dohmen (2008) found that increased incentives (when much is at stakes) induce better performance of professionals. Therefore, the mechanism could be related to the stakes. ${ }^{27}$

\footnotetext{
${ }^{25}$ Additionally, I also look at the probability of winning a medal, estimating a linear probability model. The results are reported in Table A9 in the Appendix. Similarly, having a teammate increases the probability of wining a medal for female athletes significantly, but not for male athletes.

${ }^{26}$ I further investigated the potential interaction between the heterogeneity of ability and the teammate dummy, however, no significant effects are found.

${ }^{27} \mathrm{An}$ interesting question is whether the best athletes reducing speed in preliminary heats and semifinals to conserve energy for the finals. I asked this question in the interview with the coach. The answer was "It
} 
The results are reported in Table A1 in Section A.1 in the Appendix. ${ }^{28}$

\subsection{Placebo Check 1}

One concern that remains is whether the effects could be driven by the correlation between the performances of the two teammates even within the very narrow time windows. In order to rule out this concern, I consider the same rank window size and compare the reduced form estimates at the real cutoff, the 8th rank, and two placebo cutoffs, the 6th rank and the 10th rank. Table 6 reports the reduced form coefficients of the teammate dummy. Columns (1)-(3) use normalized time and columns (4)-(6) use rank as the outcome variables. In columns (2) and (5), I report the reduced form estimates using the rank window of the baseline estimation in Table 5. In columns (1) and (4), I compare the performance of finalists whose teammate is ranked 5th or 6th with the performance of finalists whose teammate is ranked 7 th or 8 th. Note that this placebo rank window is above the real cutoff such that there is no variation in the qualification status. In columns (3) and (6), I compare the performance of finalists whose teammate is ranked 9th or 10th with the performance of finalists whose teammate is ranked 11th or 12th. Note that this placebo rank window is below the real cutoff such that there is no variation in the qualification status either. As expected, in Panel A, the coefficients of the teammate dummy are only significant in the window around the real cutoff, where the variation in qualification status actually occurs. Since the window size is fixed in all the columns, this implies that the main effect is driven by the actual variation in the qualification status rather than the correlation in performance. In Panel B, the effect of having a teammate is insignificant in all specifications.

depends." First of all, the margins are very thin, i.e. only the very top athletes have the luxury to conserve energy and may (or may not guaranteed to) still qualify for the final. Second, the semifinal ranking determines the lane position in the final. The central lanes have "better view" over other competitors, however, some athletes would like to see others while some athletes prefer not to see others and stick to their own plans.

${ }^{28}$ In Section A.1, I also show that neither being quasi-randomly seeded in the same semifinal heat (Table A2) nor being seeded in the second semifinal heat affects the semifinal performance (Table A3). 
Table 6: Reduced form estimates with the real and two placebo cutoffs

\begin{tabular}{|c|c|c|c|c|c|c|}
\hline \multicolumn{7}{|l|}{ Panel A: Female } \\
\hline & (1) & (2) & (3) & (4) & (5) & (6) \\
\hline VARIABLES & Time & Time & Time & Rank & Rank & Rank \\
\hline Teammate $($ cutoff $=6)$ & $\begin{array}{l}0.0608 \\
(0.135)\end{array}$ & & & $\begin{array}{c}0.103 \\
(0.306)\end{array}$ & & \\
\hline Teammate $($ cutoff $=8)$ & & $\begin{array}{c}-0.390 * * \\
(0.160)\end{array}$ & & & $\begin{array}{c}-0.712 * * \\
(0.323)\end{array}$ & \\
\hline Teammate $($ cutoff $=10)$ & & & $\begin{array}{l}-0.172 \\
(0.256)\end{array}$ & & & $\begin{array}{l}-0.336 \\
(0.432)\end{array}$ \\
\hline Controls & yes & yes & yes & yes & yes & yes \\
\hline Discipline FEs & yes & yes & yes & yes & yes & yes \\
\hline Championship FEs & yes & yes & yes & yes & yes & yes \\
\hline Country FEs & yes & yes & yes & yes & yes & yes \\
\hline Observations & 127 & 95 & 83 & 127 & 95 & 83 \\
\hline R-squared & 0.574 & 0.473 & 0.618 & 0.447 & 0.462 & 0.628 \\
\hline
\end{tabular}

Panel B: Male

\begin{tabular}{|c|c|c|c|c|c|c|}
\hline VARIABLES & Time & Time & Time & Rank & Rank & Rank \\
\hline Teammate $($ cutoff $=6)$ & $\begin{array}{l}0.0526 \\
(0.149)\end{array}$ & & & $\begin{array}{c}-0.0934 \\
(0.313)\end{array}$ & & \\
\hline Teammate (cutoff $=8$ ) & & $\begin{array}{c}0.0495 \\
(0.151)\end{array}$ & & & $\begin{array}{c}0.405 \\
(0.341)\end{array}$ & \\
\hline Teammate $($ cutoff $=10)$ & & & $\begin{array}{l}-0.145 \\
(0.149)\end{array}$ & & & $\begin{array}{c}-0.607 \\
(0.370)\end{array}$ \\
\hline Controls & yes & yes & yes & yes & yes & yes \\
\hline Discipline FEs & yes & yes & yes & yes & yes & yes \\
\hline Championship FEs & yes & yes & yes & yes & yes & yes \\
\hline Country FEs & yes & yes & yes & yes & yes & yes \\
\hline Observations & 93 & 93 & 80 & 93 & 93 & 80 \\
\hline R-squared & 0.661 & 0.602 & 0.699 & 0.644 & 0.583 & 0.635 \\
\hline
\end{tabular}

\subsection{Placebo Check 2}

In the second placebo check, I regress finalists' semifinal performance on the presence of a teammate in the finals within the same windows. Having a teammate in the finals should not have an impact on finalists' performance in the semifinals as it can not be perfectly predicted 
beforehand. As shown in Table 7, none of the coefficients is significant in all specifications in both the female and the male sample, which confirms that having a teammate in the finals indeed has no impact on finalists' semifinal performance.

Table 7: Placebo check using semifinal outcomes

Panel A: Female

\begin{tabular}{lcccc}
\hline & $(1)$ & $(2)$ & $(3)$ & $(4)$ \\
VARIABLES & Time $(\mathrm{SF})$ & Time $(\mathrm{SF})$ & Rank (SF) & Rank (SF) \\
\hline Teammate (F) & & & & \\
& -0.116 & 0.117 & -0.397 & -0.227 \\
& $(0.188)$ & $(0.0909)$ & $(0.468)$ & $(0.337)$ \\
& & & & \\
{$[-0.25,+0.25]$ Std } & yes & & yes & yes \\
{$[-2,+2]$ Ranks } & & yes & & \\
& & & & yes \\
Controls & yes & yes & yes & yes \\
Discipline FEs & yes & yes & yes & yes \\
Championship FEs & yes & yes & yes & yes \\
Country FEs & yes & yes & yes & \\
& & & & 95 \\
Observations & 97 & 95 & 97 & 0.391 \\
R-squared & 0.464 & 0.507 & 0.378 & \\
\hline \hline
\end{tabular}

Panel B: Male

\begin{tabular}{lcccc}
\hline VARIABLES & Time (SF) & Time (SF) & Rank (SF) & Rank (SF) \\
\hline Teammate (F) & 0.103 & -0.0589 & 0.477 & 0.272 \\
& $(0.113)$ & $(0.118)$ & $(0.426)$ & $(0.383)$ \\
& & & & \\
{$[-0.25,+0.25]$ Std } & yes & & yes & yes \\
{$[-2,+2]$ Ranks } & & yes & & \\
& & & & yes \\
Controls & yes & yes & yes & yes \\
Discipline FEs & yes & yes & yes & yes \\
Championship FEs & yes & yes & yes & yes \\
Country FEs & yes & yes & yes & \\
& & & & 93 \\
Observations & 90 & 93 & 90 & 0.440 \\
R-squared & 0.595 & 0.475 & 0.477 & \\
\hline
\end{tabular}

Note: Robust standard errors in parentheses.

Normalized time is the ratio of own time in the final over the average time of the sixteen athletes in the semifinal, and multiplied by 100 . 


\subsection{Effect Heterogeneity}

This section investigates the heterogeneity of the main effects in the following dimensions: age, experience, semifinal ranking and the individualism score of the country (The tables of the results can be found in Section A. 2 in the Appendix.). ${ }^{29}$

Firstly, I test whether the main effects of having a teammate in the same finals differ with respect to athletes' age by interacting the teammate dummy with focal athletes' age (demeaned). The interaction term has the opposite sign compared to the main effects in all the four specifications and is marginally significant in three specifications (Table A4). This suggests that older female athletes are slightly less prone to the peer effects studied. Secondly, focal athletes have different experience in participating at the World Championships. I test whether the main effects differ with respect to athletes' experience by interacting the teammate dummy with focal athletes' number of finals participated during the whole sample period (demeaned). The interaction term has the same sign as the main effects but is insignificant (Table A5). Thus, one cannot reject the null hypothesis that the main effects are the same for experienced and less experienced athletes.

Thirdly, I test whether the main effects vary according to athlete's own semifinal ranking (demeaned). As in the case of experience, one cannot reject the null hypothesis that the main effects are the same for higher ranked and lower ranked athletes (Table A6).

Finally, I also exploit cultural heterogeneity in terms of individualism. ${ }^{30}$ I map athletes' nationality to the individualism index (IDV, demeaned ) measured for the country. In the female sample, the coefficients of the interaction term are positive and marginally significant in two specifications (Table A7), suggesting that female athletes from more individualistic countries are less prone to the peer effects studied.

In summary, while I find weak evidence that the effects of having a teammate in the

\footnotetext{
${ }^{29}$ While I report the results of the heterogeneity analysis in both female and the male sample for completeness, I only discuss the results of the female sample in the text as I only find an effect among female athletes.

${ }^{30}$ Hofstede introduced an individualism index that explores the degree to which individuals are integrated into groups (Kieser 1994). Individualists emphasise the "I" versus the "we", whereas the collectivists do the opposite. For example, USA as a typical individualistic country scores 91 and China as a typical collective country scores 20 on a scale of 0 to 100. Although swimming is not a team sport, athletes representing the same national team may still feel belonging to the same group. One could expect that having a teammate in the same tournament might mean more to the collectivists than to the individualists.
} 
same finals is slightly stronger for younger athletes and athletes from less individualistic countries, I do not find evidence that the main effects vary with experience or ability.

\section{Potential Mechanisms}

This section discusses two potential mechanisms proposed in the literature that may drive the observed phenomena. They are intra-team competition and mitigated psychosocial pressure.

\subsection{Intra-team Competition}

Having a teammate in the same final may switch on intra-team competition as the teammate is the only national competitor that is relevant for sponsorship and other economic sources at the national level. Athletes may be additionally motivated through status incentives (Besley and Ghatak 2008; Moldovanu, Sela and Shi 2007) and explicitly set the goal as "beat-theteammate”. Charness, Masclet and Villeval (2010) found in a lab experiment that subjects exert effort in a status competition even without any monetary incentives. Similarly, Azmat and Iriberri (2010) showed in the lab that, despite being rewarded via a piece rate for their efforts, subjects that are given information about their peers' performance makes significantly higher effort than the control group without such feedback. Furthermore, since high-stake prizes are awarded to the top performers in this setup, the competition necessarily creates income inequality. Some athletes may have inequality/inequity aversion (Fehr and Schmidt 1999). If so, the intra-team competition can be further intensified by avoiding strong negative inequality aversion. For example, if an athlete anticipates that she will sense strong negative inequality aversion when losing to her teammate, she may increase effort to prevent such a situation (Grund and Sliwka 2005).

The intensity of the intra-team competition may depend on the teammate's ability relative to the focal athlete. According to Locke and Latham (2002), the highest level of effort occurs when the goal is moderate and the lowest level of effort occurs when the goal is too easy or too difficult. If the teammate is far behind or ahead in the previous ranking, the goal of "beat-the-teammate" would be too easy or too difficult. Therefore, if having a teammate 
switches on intra-team competition and its intensity varies according to the relative ability of the teammate, the main effects should be strongest when the two teammates are close competitors. This can be tested empirically. I create a variable "close competitor" by taking the absolute value of the rank difference between the two teammates in the preliminary heats: ${ }^{31}$

$$
\text { close competitor }= \begin{cases}1 & \text { if rank difference } \subset[0,4] \\ 0 & \text { if rank difference } \subset[5,9] \\ -1 & \text { if rank difference } \subset[10,15] .\end{cases}
$$

Extending the main empirical specification in Equation 4.1, I interact the teammate dummy variable with the "close competitor" variable, as shown in Equation 6.1. ${ }^{32}$ The hypothesis above predicts a negative sign of the interaction term $\left(\gamma_{2}\right){ }^{33}$

$$
\begin{aligned}
\text { Performance }_{i, t} & =\gamma_{1} \text { Teammate }_{i, t}+\gamma_{2} \text { Teammate }_{i, t} \times \text { Close Competitor }_{i j, t} \\
& +\gamma_{3} \text { Close Competitor }_{i j, t}+\theta_{1} \text { Age }_{i, t}+\theta_{2} \text { Age }_{j, t}+\theta_{3} \text { Ability }_{i, t}+\nu_{i, t}
\end{aligned}
$$

Table 8 reports the estimated results. In the female sample (panel A), the estimated coefficients of the interaction term, $\gamma_{2}$, are all positive except in column (4), but none of them is significant. In the male sample (panel B), the signs of the interaction term are negative and insignificant in columns (1)-(3) and barely significant in column (4). Therefore, the effect of having a teammate does not seem to vary according to the relative ability of the teammate.

This, however, does not rule out that the intra-team competition can be switched on simply by the existence of a teammate. A related (but different) phenomenon is the "Queen Bee" behavior which is used to describe the behavior of senior women towards other women

\footnotetext{
${ }^{31}$ The absolute rank difference in the preliminary heat spans from 0 to 15 , as the highest rank is 1 and the lowest is 16 for those who qualify for the semifinals.

${ }^{32}$ The teammate dummy variable is instrumented by the indicator of the teammate's rank in the semifinal, and the interaction term is instrumented by the interaction of the rank indicator with the variable "close competitor" in the first stage.

${ }^{33}$ I do not aim to fully detect a nonmonotic effect. This is rather a conservative test to check whether the effect is amplified when the two are close competitors. Moreover, this test does not rule out that the intra-team competition can be switched on simply by the existence of a teammate.
} 
Table 8: The effects of being close competitors

Panel A: Female

\begin{tabular}{lcccc}
\hline & $(1)$ & $(2)$ & $(3)$ & $(4)$ \\
VARIABLES & Time & Time & Rank & Rank \\
\hline & & & & \\
Teammate & $-0.704^{* * *}$ & $-0.495^{* *}$ & $-1.370^{* * *}$ & $-0.854^{* *}$ \\
& $(0.238)$ & $(0.216)$ & $(0.516)$ & $(0.414)$ \\
Teammate $\times$ Close competitor & 0.340 & 0.177 & 0.469 & -0.00306 \\
& $(0.303)$ & $(0.284)$ & $(0.643)$ & $(0.576)$ \\
Close competitor & -0.355 & -0.0997 & -0.244 & 0.317 \\
& $(0.250)$ & $(0.236)$ & $(0.482)$ & $(0.442)$ \\
& & & & \\
{$[-0.25,+0.25]$ Std } & yes & & yes & \\
{$[-2,+2]$ Ranks } & & yes & & yes \\
& & & & \\
Controls & yes & yes & yes & yes \\
Discipline FEs & yes & yes & yes & yes \\
Championship FEs & yes & yes & yes & yes \\
Country FEs & yes & yes & yes & yes \\
& & & & \\
F-statistics of Instrument & 231.075 & 293.792 & 231.075 & 293.792 \\
Observations & 97 & 95 & 97 & 95 \\
R-squared & 0.461 & 0.468 & 0.388 & 0.453 \\
\hline \hline
\end{tabular}

Panel B: Male

\begin{tabular}{|c|c|c|c|c|}
\hline VARIABLES & Time & Time & Rank & Rank \\
\hline Teammate & $\begin{array}{c}0.186 \\
(0.175)\end{array}$ & $\begin{array}{c}0.141 \\
(0.171)\end{array}$ & $\begin{array}{c}0.532 \\
(0.402)\end{array}$ & $\begin{array}{c}0.647 * \\
(0.388)\end{array}$ \\
\hline Teammate $\times$ Close competitor & $\begin{array}{l}-0.141 \\
(0.241)\end{array}$ & $\begin{array}{l}-0.209 \\
(0.223)\end{array}$ & $\begin{array}{l}-0.775 \\
(0.517)\end{array}$ & $\begin{array}{l}-0.970^{*} \\
(0.503)\end{array}$ \\
\hline Close competitor & $\begin{array}{c}-0.0996 \\
(0.177)\end{array}$ & $\begin{array}{l}-0.0219 \\
(0.160)\end{array}$ & $\begin{array}{c}0.241 \\
(0.400)\end{array}$ & $\begin{array}{c}0.469 \\
(0.372)\end{array}$ \\
\hline $\begin{array}{l}{[-0.25,+0.25] \text { Std }} \\
{[-2,+2] \text { Ranks }}\end{array}$ & yes & yes & yes & yes \\
\hline Controls & yes & yes & yes & yes \\
\hline Discipline FEs & yes & yes & yes & yes \\
\hline Championship FEs & yes & yes & yes & yes \\
\hline Country FEs & yes & yes & yes & yes \\
\hline F-statistics of Instrument & 143.537 & 158.526 & 143.537 & 158.526 \\
\hline Observations & 90 & 93 & 90 & 93 \\
\hline R-squared & 0.662 & 0.602 & 0.644 & 0.581 \\
\hline
\end{tabular}


in organizations (Mavin 2008). Since the focal athletes are on average higher ranked than their teammates who barely qualified, they may behave as "Queen Bees" and enhance the intra-team competition.

\subsection{Mitigated Psychosocial Pressure}

Having a teammate in the same final may mitigate the psychosocial pressure in the competition. "Racing is $10 \%$ physical and $90 \%$ mental.", said the seven-time gold medalist Mark Spitz. Athletes in elite level tournaments are under enormous pressure which may tighten athletes' muscles, choke off their breathing and jeopardize their performance. ${ }^{34}$ The phenomenon of performance decrements under circumstances that increase the importance of the outcome is defined as "choking under pressure" (Baumeister 1984; Hill et al. 2009). In the economics literature, the the performance under psychological/psychosocial pressure in tournaments has been tested, for instance, using penalty kicks in football matches. Dohmen (2008) found that players of the home team (more pressure) are more likely to choke in the penalty kicks; Apesteguia and Palacios-Huerta (2010) found that teams taking the first kick in sequence (less pressure) are more likely to win the penalty, while Kocher, Lenz and Sutter (2012) did not find significant differences of the kicking order in the winning probability with a larger sample.

Gender differences under psychosocial pressure or stress have been frequently documented in the literature. Females perform worse in the exam under time pressure (De Paola and Gioia 2016) and stress (Cahlikova, Cingl and Levely 2017) than males in competitions, and increasing competitive pressure widens the gender gap in performance in two-stage elimination contests (Iriberri and Rey-Biel 2018). Similarly, Cai et al. (2018) suggests that gender differences in response to pressure underpin gender differences in scholastic performance in high pressure settings. In sports, female athletes are found to exhibit a higher level of stress than male athletes in swimming training sessions (Raglin, Morgan and O'Connor 1991). At elite level, Paserman (2007) also reported that female tennis players make more

\footnotetext{
${ }^{34}$ Many athletes race faster in practice, relays or off events than they do at big meets. See for example, https://www.competitivedge.com/swim-series-biggest-secret-swimming-fast-under-pressure.
} 
mistakes under pressure than male players. Therefore, while male athletes' performance is more immune to psychosocial pressure, female athletes' performance could be less impaired if the pressure is mitigated.

There can be several channels through which having a teammate can mitigate psychosocial pressure. For instance, not representing the country alone may reduce the pressure if the outcome is more important for the country than for the individual. The teammate may also provide motivational support - a key element in the social support - to each other which helps them to cope better with psychosocial pressure. For example, a positive facial expression, a confident gesture, or a motivating word in the locker room or waiting area may give enough motivation boost. Gender differences have been found in the literature on social support too. Women provide more social support to others (Thoits 1995; Taylor et al. 2000), are more likely to seek out social support to deal with psychosocial pressure or stress (Tamres, Janicki and Helgeson 2002), and benefit more from social support (Schwarzer and Leppin 1989). However, it is difficult to verify empirically whether athletes actually receive motivational support in this context as such support can be difficult to observe or recognize by the others. Therefore, this channel is speculative in the present context. Although there is no formal test for this channel, many athletes do mention that they were motivated by their teammate in interviews after the competitions.

Finally, intra-team competition itself can be a source of psychosocial pressure. As the literature suggests, anything that increases the importance of one's performance can cause "choking under pressure". The presence of a teammate creates intra-team competition which itself increases the importance of the competition, e.g. more people in the country will watch it and talk about who is the better one; sponsors may write relative performancecontingent contracts. A teammate is thus likely to be a "frenemy", i.e. she may provide motivational support to cope with tournament pressure and at the same time also creates intra-team competition that increases pressure. Therefore, what we observe here can rather be a net effect of the two mechanisms. 


\section{Conclusion}

This paper investigates whether having a teammate in the competing peer group affects individual's performance in high-stakes swimming tournaments. I identify the causal effects of the peer group's composition by applying the concept of regression discontinuity design. Female athletes perform better when having a teammate in the same finals while male athletes do not perform differently in the same scenario. I discuss two potential mechanisms, enhanced intra-team competition and mitigated psychosocial pressure, that could autonomously or jointly generate the observed effects. Both mechanisms are consistent with the literature on peer effects as well as the literature on gender differences in competitions.

This study also has some limitations. First, athletes participate only in same-sex competitions. This is an inevitable limitation for the majority of studies that use real sports data. Future research could investigate the effects of a peer group's composition in mixed-sex competitions. The second limitation is that the discussion of the two potential mechanisms is rather suggestive. It is hard to identify the true mechanism underlying the peer effects using observational data. After all, individuals can take actions without being fully aware of what is motivating them (Murphy 2001). Future research could, for example, measure individuals' actual psychosocial pressure using survey questionnaire or medical devices in different exogenous scenarios. Finally, there is always a trade-off between internal identification and external validity. The identification strategy in this paper is only valid for athletes having a teammate within a narrow window around the qualification cutoff. To extend the results to a broader range of athletes one would need a different identification strategy such as randomised presence of a teammate. Moreover, although professional individual sports tournaments share a lot in common with competitions in firms, they do differ in important aspects. Competitions among employees in firms are typically weighted over multiple dimensions, more continuous, and over a longer horizon which allows more within competition dynamics that are not captured in this setup. 


\section{References}

Andersen, Steffen, Seda Ertaç, Uri Gneezy, Moshe Hoffman and John A List. 2011. "Stakes matter in ultimatum games." American Economic Review 101(7):3427-39.

Angrist, Joshua D and Jörn-Steffen Pischke. 2008. Mostly harmless econometrics: An empiricist's companion. Princeton University Press.

Angrist, Joshua D and Kevin Lang. 2004. "Does school integration generate peer effects? Evidence from Boston's Metco Program.” American Economic Review 94(5):1613-1634.

Apesteguia, Jose and Ignacio Palacios-Huerta. 2010. "Psychological pressure in competitive environments: Evidence from a randomized natural experiment." American Economic Review 100(5):2548-64.

Ariely, Dan, Uri Gneezy, George Loewenstein and Nina Mazar. 2009. "Large stakes and big mistakes.” Review of Economic Studies 76(2):451-469.

Athey, Susan and Guido W Imbens. 2017. The econometrics of randomized experiments. In Handbook of Economic Field Experiments. Vol. 1 Elsevier pp. 73-140.

Azmat, Ghazala and Nagore Iriberri. 2010. "The importance of relative performance feedback information: Evidence from a natural experiment using high school students." Journal of Public Economics 94(7-8):435-452.

Balafoutas, Loukas, Subhasish M Chowdhury and Henning Plessner. 2019. "Applications of Sports Data to Study Decision Making.”.

Bandiera, Oriana, Iwan Barankay and Imran Rasul. 2010. "Social incentives in the workplace." Review of Economic Studies 77(2):417-458.

Baumeister, Roy F. 1984. "Choking under pressure: self-consciousness and paradoxical effects of incentives on skillful performance." Journal of Personality and Social Psychology 46(3):610.

Beshears, John, James J Choi, David Laibson, Brigitte C Madrian and Katherine L Milkman. 
2015. "The effect of providing peer information on retirement savings decisions." Journal of Finance 70(3):1161-1201.

Besley, Timothy and Maitreesh Ghatak. 2008. "Status incentives." American Economic Review 98(2):206-211.

Beugnot, Julie, Bernard Fortin, Guy Lacroix and Marie Claire Villeval. 2013. "Social networks and peer effects at work.” IZA Discussion Paper No. 7521.

Bond, Robert M, Christopher J Fariss, Jason J Jones, Adam DI Kramer, Cameron Marlow, Jaime E Settle and James H Fowler. 2012. “A 61-million-person experiment in social influence and political mobilization.” Nature 489(7415):295-298.

Bruhin, Adrian, Lorenz Goette, Simon Haenni and Lingqing Jiang. 2015. "Spillovers of Prosocial Motivation: Evidence from an Intervention Study on Blood Donors.”. CEPR Discussion Paper No. DP10345.

Cahlikova, Jana, Lubomir Cingl and Ian Levely. 2017. "How stress affects performance and competitiveness across gender." Working Paper of the Max Plank Institute for Tax Law and Public Finance, No.2017-1.

Cai, Xiqian, Yi Lu, Jessica Pan and Songfa Zhong. 2018. “Gender Gap Under Pressure: Evidence from China's National College Entrance Examination." Review of Economics and Statistics . 10.1162/rest_a_00749.

Cameron, A Colin and Douglas L Miller. 2015. “A practitioner's guide to cluster-robust inference." Journal of Human Resources 50(2):317-372.

Carroll, Nathan J. 2012. "How does status affect behaviour? A natural experiment with golf players.” Mimeo, University of Regensburg.

Charness, Gary, David Masclet and Marie Claire Villeval. 2010. "Competitive preferences and status as an incentive: Experimental evidence." Groupe d'Analyse et de Théorie Economique Working Paper No. 1016.

Chen, Yan, F Maxwell Harper, Joseph Konstan and Sherry Xin Li. 2010. "Social com- 
parisons and contributions to online communities: A field experiment on movielens." American Economic Review 100(4):1358-1398.

Chen, Zhuoqiong Charlie, David Ong and Roman M Sheremeta. 2015. "The gender difference in the value of winning." Economics Letters 137:226-229.

Cipollone, Piero and Alfonso Rosolia. 2007. "Social interactions in high school: Lessons from an earthquake.” American Economic Review 97(3):948-965.

De Paola, Maria and Francesca Gioia. 2016. "Who performs better under time pressure? Results from a field experiment." Journal of Economic Psychology 53:37-53.

Dohmen, Thomas J. 2008. "Do professionals choke under pressure?" Journal of Economic Behavior \& Organization 65(3-4):636-653.

Duflo, Esther and Emmanuel Saez. 2002. "Participation and investment decisions in a retirement plan: The influence of colleagues choices." Journal of Public Economics 85(1):121148.

Falk, Armin and Andrea Ichino. 2006. "Clean evidence on peer effects." Journal of Labor Economics 24(1):39-57.

Fehr, Ernst and Klaus M Schmidt. 1999. "A theory of fairness, competition, and cooperation." Quarterly Journal of Economics 114(3):817-868.

Garratt, Rodney J, Catherine Weinberger and Nick Johnson. 2013. "The state street mile: Age and gender differences in competition aversion in the field." Economic Inquiry 51(1):806-815.

Gerber, Alan S, Donald P Green and Christopher W Larimer. 2008. "Social pressure and voter turnout: Evidence from a large-scale field experiment." American Political Science Review 102(1):33-48.

Gneezy, Uri and Aldo Rustichini. 2004. "Gender and competition at a young age.” American Economic Review 94(2):377-381. 
Gould, Eric D, Victor Lavy and Daniele M Paserman. 2009. "Does immigration affect the long-term educational outcomes of natives? Quasi-experimental evidence." Economic Journal 119(540):1243-1269.

Graff, Frederik, Christian Grund and Christine Harbring. 2018. "Competing on the Holodeck: The Effect of Virtual Peers and Heterogeneity in Dynamic Tournaments.”.

Grund, Christian and Dirk Sliwka. 2005. "Envy and compassion in tournaments." Journal of Economics \& Management Strategy 14(1):187-207.

Guryan, Jonathan, Kory Kroft and Matthew J Notowidigdo. 2009. "Peer Effects in the Workplace: Evidence from Random Groupings in Professional Golf Tournaments." American Economic Journal: Applied Economics 1(4):34-68.

Hahn, Jinyong, Petra Todd and Wilbert Van der Klaauw. 2001. "Identification and estimation of treatment effects with a regression-discontinuity design.” Econometrica 69(1):201209.

Halliday, Timothy J and Sally Kwak. 2012. "What is a peer? The role of network definitions in estimation of endogenous peer effects.” Applied Economics 44(3):289-302.

Herbst, Daniel and Alexandre Mas. 2015. "Peer effects on worker output in the laboratory generalize to the field." Science 350(6260):545-549.

Hill, Brian. 2014. "The heat is on: Tournament structure, peer effects, and performance." Journal of Sports Economics 15(4):315-337.

Hill, Denise M, Sheldon Hanton, Scott Fleming and Nic Matthews. 2009. "A re-examination of choking in sport.” European Journal of Sport Science 9(4):203-212.

Hoxby, Caroline. 2000. Peer effects in the classroom: Learning from gender and race variation. Technical report National Bureau of Economic Research.

Iriberri, Nagore and Pedro Rey-Biel. 2018. "Competitive Pressure Widens the Gender Gap in Performance: Evidence from a Two-Stage Competition in Mathematics." Economic Journal . 10.1111/ecoj.12617. 
Kieser, Alfred. 1994. "Book Reviews: Geert Hofstede: Cultures and Organizations. Software of the Mind: 1991, Maidenhead, UK: McGraw-Hill. 279 pages." Organization Studies 15(3):457-460.

Kießling, Lukas, Jonas Radbruch and Sebastian Schaube. 2018. “The Impact of SelfSelection on Performance.” IZA Discussion Paper No. 11365.

Kocher, Martin G, Marc V Lenz and Matthias Sutter. 2012. "Psychological pressure in competitive environments: New evidence from randomized natural experiments." Management Science 58(8):1585-1591.

Lalive, Rafael and M. Alejandra Cattaneo. 2009. "Social Interactions and Schooling Decisions." Review of Economics and Statistics 91(3):457-477.

Lavy, Victor and Analia Schlosser. 2011. "Mechanisms and impacts of gender peer effects at school.” American Economic Journal: Applied Economics 3(2):1-33.

Lavy, Victor, M Daniele Paserman and Analia Schlosser. 2011. "Inside the black box of ability peer effects: Evidence from variation in the proportion of low achievers in the classroom.” Economic Journal 122(559):208-237.

Lazear, Edward P and Sherwin Rosen. 1981. "Rank-Order Tournaments as Optimum Labor Contracts." Journal of Political Economy 89(5):841-864.

Locke, Edwin A and Gary P Latham. 2002. "Building a practically useful theory of goal setting and task motivation: A 35-year odyssey." American Psychologist 57(9):705.

Manski, Charles F. 1993. "Identification of endogenous social effects: The reflection problem.” Review of Economic Studies 60(3):531-542.

Mas, Alexandre and Enrico Moretti. 2009. "Peers at Work." American Economic Review 99(1):112-145.

Mavin, Sharon. 2008. 'Queen bees, wannabees and afraid to bees: no more 'best enemies' for women in management?" British Journal of Management 19:S75-S84. 
Moldovanu, Benny, Aner Sela and Xianwen Shi. 2007. "Contests for status.” Journal of Political Economy 115(2):338-363.

Murphy, Sheila T. 2001. "Feeling without thinking: Affective primacy and the nonconscious processing of emotion." Unraveling the complexities of social life: A festschrift in honor of Robert B. Zajonc pp. 39-53. Washington, DC, US: American Psychological Association.

Niederle, Muriel and Lise Vesterlund. 2007. "Do women shy away from competition? Do men compete too much?" Quarterly Journal of Economics 122(3):1067-1101.

Niederle, Muriel and Lise Vesterlund. 2011. “Gender and competition.” Annu. Rev. Econ. 3(1):601-630.

Paserman, M. 2007. "Gender differences in performance in competitive environments: evidence from professional tennis players.” IZA Discussion Paper No. 2834.

Raglin, JS, WP Morgan and PJ O’Connor. 1991. “Changes in mood states during training in female and male college swimmers." International Journal of Sports Medicine 12(06):585-589.

Sacerdote, Bruce. 2001. "Peer effects with random assignment: Results for Dartmouth roommates." Quarterly Journal of Economics 116(2):681-704.

Schwarzer, Ralf and Anja Leppin. 1989. "Social support and health: A meta-analysis." Psychology and Health 3(1):1-15.

Slonim, Robert and Alvin E Roth. 1998. "Learning in high stakes ultimatum games: An experiment in the Slovak Republic.” Econometrica 66(3):569.

Sunde, Uwe. 2009. "Heterogeneity and performance in tournaments: a test for incentive effects using professional tennis data.” Applied Economics 41(25):3199-3208.

Tamres, Lisa K, Denise Janicki and Vicki S Helgeson. 2002. "Sex differences in coping behavior: A meta-analytic review and an examination of relative coping." Personality and Social Psychology Review 6(1):2-30. 
Taylor, Shelley E, Laura Cousino Klein, Brian P Lewis, Tara L Gruenewald, Regan AR Gurung and John A Updegraff. 2000. "Biobehavioral responses to stress in females: tend-and-befriend, not fight-or-flight." Psychological Review 107(3):411.

Thoits, Peggy A. 1995. "Stress, coping, and social support processes: Where are we? What next?" Journal of Health and Social Behavior pp. 53-79.

Van Veldhuizen, Roel, Hessel Oosterbeek and Joep Sonnemans. 2018. "Peers at work: Evidence from the lab.” PloS one 13(2):e0192038.

Yamane, Shoko and Ryohei Hayashi. 2011. "Gender Differences in Competition: Evidence from Swimming Data.” Journal of Behavioral Economics and Finance 4:47-50.

Yamane, Shoko and Ryohei Hayashi. 2015. "Peer Effects among Swimmers." Scandinavian Journal of Economics 117(4):1230-1255. 


\section{A Appendix}

\section{A.1 Semifinal Analysis}

This section performs three sets of analysis for the semifinals: i) whether having a teammate in the semifinals affects the semifinal performance; ii) whether being seeded in the same semifinal heat as the teammate (conditional on having a teammate in the semifinals) affects the semifinal performance; and iii) whether being seeded in the second semifinal heat has an advantage in qualifying for the finals.

\section{Having a Teammate in The Semifinals}

This analysis uses the same data from the long course FINA World Championships (20032015) and applies the same discontinuity design as in the main analysis for the finals. Since the top 16 athletes of the preliminary heats qualify for the semifinals, the cutoff is adapted to the 16th rank. Table A1 presents the estimated coefficients of having a teammate that barely qualified for the same semifinals in the female (Panel A) and male sample (Panel B). In columns (1) and (2) I consider the normalized time as the outcome variable. In columns (3) and (4) I consider the qualification status for the finals as the outcome variable. ${ }^{35}$ The table reports results for both the time and the rank window. The time window is quarter of a standard deviation of the time used in the preliminary heats above and below the cutoff and the rank window is 2 ranks above and below the cutoff. ${ }^{36}$ The coefficients of teammate are insignificant in all the columns in both the female and the male sample.

A direct comparison of the results for the finals and the semifinals is not straightforward. However, it is not surprising that the effects of having a teammate are weaker (or insignificant) in the semifinals where the championship is not yet at stake.

\footnotetext{
${ }^{35}$ Unlike in the finals where rank determines the prize money and fame, in the semifinals what matters most is qualification for the finals. Therefore, I use the latter as the outcome variable in the semifinal analysis.

${ }^{36}$ I checked that using more narrow windows yields similar results.
} 
Table A1: Two-stage least squares estimates of the effect of having a teammate in the semifinal on the semifinal performance

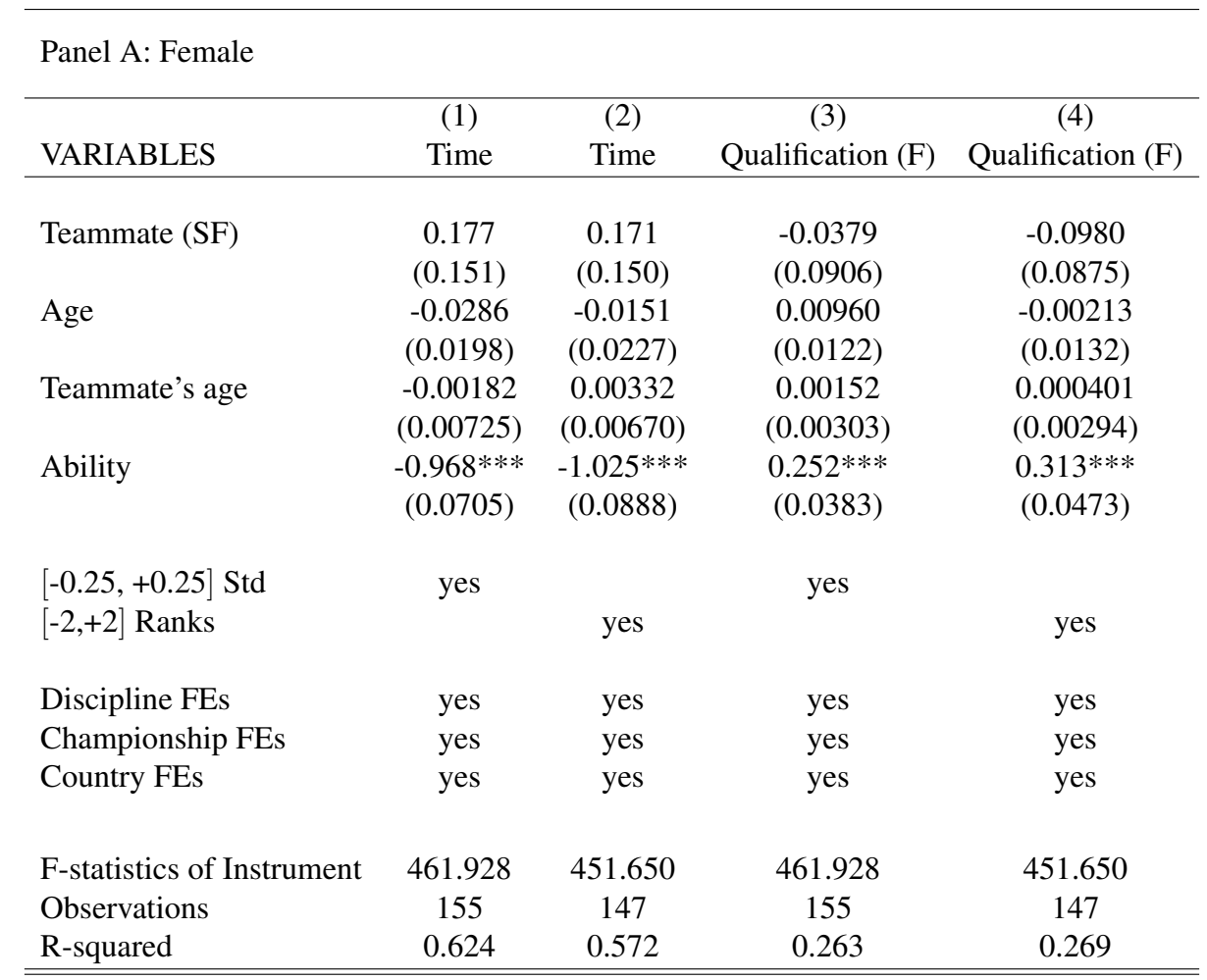

Panel B: Male

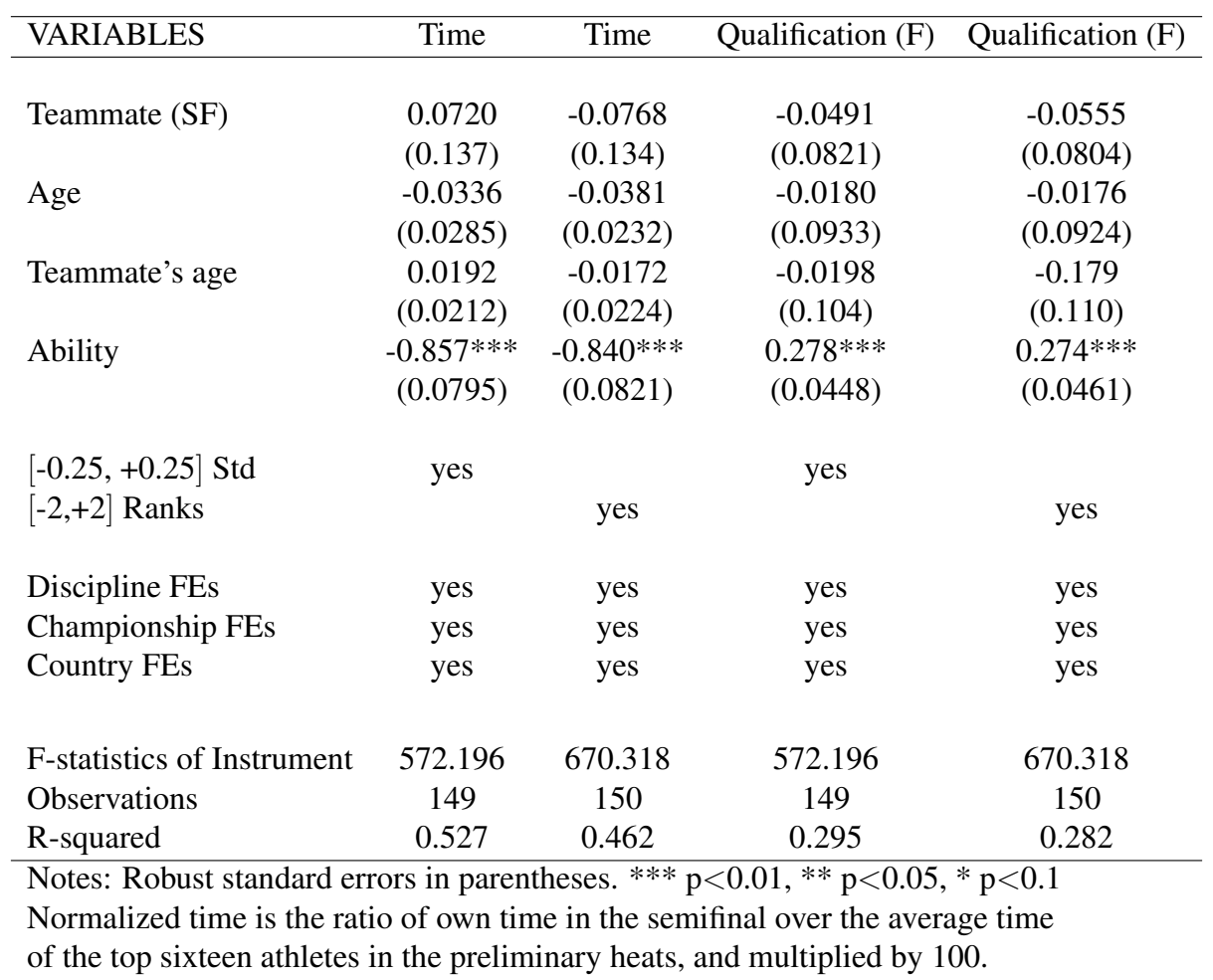




\section{Having A Teammate in the Same Semifinal Heat}

There are two semifinal heats. Conditional on having a teammate in semifinals, the focal athletes and their teammates can be seeded either in the same heat or two different heats. The former means that the teammate is physically present while the latter means that the teammate is physically absent albeit still in the competition. Whether being seeded in the same heat in the semifinal can be considered as quasi-random, given the following FINA rule:

FINA SW 3.1.1.2: If two heats, the fastest swimmer shall be seeded in the second heat, next fastest in the first heat, next fastest in the second heat, next in the first heat, etc. $^{37}$

I regress the semifinal performance on a dummy indicating whether the teammate is in the same heat or not, together with the controls and three sets of fixed effects. The performance is measured in normalized time and in terms of the qualification status for the finals. Table A2 reports the estimated coefficients. Columns (1) and (2) show the results for the female sample and columns (3) and (4) for the male sample. The results show that having a teammate in the same semifinal heat does not have a significant effect on the semifinal performance.

\section{Second Heat Advantage?}

The last set of analysis investigates whether there is a second heat advantage as the athletes in the second heat start later and have access to more information about other athletes' performance. ${ }^{38}$ I regress the focal athlete's qualification status for the finals on a dummy indicating whether the athlete is seeded in the second heat, together with the controls and

\footnotetext{
${ }^{37}$ The previous ranks in semifinal heat 1 are 2,4,6,8,10,12,14,16 and in semifinal heat 2 they are $1,3,5,7,9,11,13,15$.

${ }^{38}$ See Hill (2014), for example. However, notice that the heats in Hill (2014) are from running tournaments while the heats in my data are from swimming tournaments. They are different in two aspects: 1) the seeding rules are different. Running heat 1: 1,4,5,8,9,12,13,16,17,20; Running heat 2: 2,3,6,7,10,11,14,15,18,19; (Swimming heats see in the footnote 31.) and 2) the qualification rules are different. Running tournaments use a combination of rank qualification and time qualification while swimming tournaments use solely time qualification.
} 
Table A2: The effects of having a teammate in the same semifinal heat on semifinal performance

\begin{tabular}{lcccc}
\hline & $\begin{array}{c}(1) \\
\text { Female }\end{array}$ & $\begin{array}{c}\text { Female } \\
\text { Qualification (F) }\end{array}$ & $\begin{array}{c}\text { Male } \\
\text { Time (SF) }\end{array}$ & $\begin{array}{c}\text { Male } \\
\text { Qualification (F) }\end{array}$ \\
\hline VARIABLES & & & & \\
Teammate in Same SF heat & 0.0169 & -0.0163 & -0.00946 & 0.0305 \\
& $(0.0631)$ & $(0.0321)$ & $(0.0671)$ & $(0.0339)$ \\
Controls & yes & yes & yes & yes \\
Discipline FEs & yes & yes & yes & yes \\
Championship FEs & yes & yes & yes & yes \\
Country FEs & yes & yes & yes & yes \\
& & & & \\
Observations & 688 & 688 & 645 & 645 \\
R-squared & 0.611 & 0.309 & 0.495 & 0.285 \\
\hline
\end{tabular}

Note: Robust standard errors in parentheses.

three sets of fixed effects. Table A3 reports the estimated coefficients. By design of the FINA rule, the average rank in heat 1 is higher than in heat 2 , therefore, athletes seeded in the second heat are on average better in the first place. The coefficients of the second heat dummy are significantly positive in columns (1) and (3). However, once controlling for ability, there seems to be no significant advantage of being seeded in the second heat.

Table A3: The effect of being seeded in the second heat on qualification stuatus for the final

\begin{tabular}{lcccc}
\hline VARIABLES & $(1)$ & $(2)$ & $(3)$ & $(4)$ \\
& Female & Female & Male & Male \\
\hline Second heat & $0.0679^{* * *}$ & -0.00744 & $0.0701^{* * *}$ & 0.0235 \\
& $(0.0248)$ & $(0.0177)$ & $(0.0254)$ & $(0.0179)$ \\
Ability & & $0.282^{* * *}$ & & $0.351^{* * *}$ \\
& & $(0.00739)$ & & $(0.00867)$ \\
Controls & yes & yes & yes & yes \\
Discipline FEs & yes & yes & yes & yes \\
Championship FEs & yes & yes & yes & yes \\
Country FEs & yes & yes & yes & yes \\
& & & & \\
Observations & 1,455 & 1,453 & 1,454 & 1,451 \\
R-squared & 0.008 & 0.509 & 0.007 & 0.512 \\
\hline \multicolumn{2}{l}{ Robust standard errors in parentheses. $* * * \mathrm{p}<0.01, * * \mathrm{p}<0.05, * \mathrm{p}<0.1$}
\end{tabular}




\section{A.2 Heterogeneity Analysis}

Table A4: Heterogeneity in age

\begin{tabular}{|c|c|c|c|c|}
\hline \multicolumn{5}{|l|}{ Panel A: Female } \\
\hline \multirow[b]{2}{*}{ VARIABLES } & $(1)$ & $(2)$ & $(3)$ & $(4)$ \\
\hline & Time & Time & Rank & Rank \\
\hline \multirow[t]{2}{*}{ Teammate } & $-0.601 * * *$ & $-0.389 * *$ & $-1.205 * * *$ & $-0.720 * *$ \\
\hline & $(0.201)$ & $(0.170)$ & $(0.442)$ & $(0.340)$ \\
\hline \multirow[t]{2}{*}{ Teammate $\times$ Age } & $0.168^{*}$ & $0.142 *$ & 0.199 & $0.247 *$ \\
\hline & $(0.0879)$ & $(0.0813)$ & $(0.134)$ & $(0.133)$ \\
\hline \multirow[t]{2}{*}{ Age } & -0.106 & -0.105 & -0.142 & $-0.203 * *$ \\
\hline & $(0.0809)$ & $(0.0641)$ & $(0.112)$ & $(0.0923)$ \\
\hline \multirow[t]{2}{*}{ Teammate's age } & -0.00486 & -0.00197 & 0.00580 & -0.00202 \\
\hline & $(0.0229)$ & $(0.0218)$ & $(0.0578)$ & $(0.0409)$ \\
\hline \multirow[t]{2}{*}{ Ability } & $-1.023^{* * *}$ & $-1.182 * * *$ & $-1.818 * * *$ & $-2.210 * * *$ \\
\hline & $(0.119)$ & $(0.128)$ & $(0.241)$ & $(0.252)$ \\
\hline$[-0.25,+0.25] \mathrm{Std}$ & yes & & yes & \\
\hline$[-2,+2]$ Ranks & & yes & & yes \\
\hline Discipline FEs & yes & yes & yes & yes \\
\hline Championship FEs & yes & yes & yes & yes \\
\hline Country FEs & yes & yes & yes & yes \\
\hline F-statistics of Instrument & 139.993 & 166.561 & 139.993 & 166.561 \\
\hline Observations & 97 & 95 & 97 & 95 \\
\hline R-squared & 0.482 & 0.490 & 0.390 & 0.463 \\
\hline
\end{tabular}

Panel B: Male

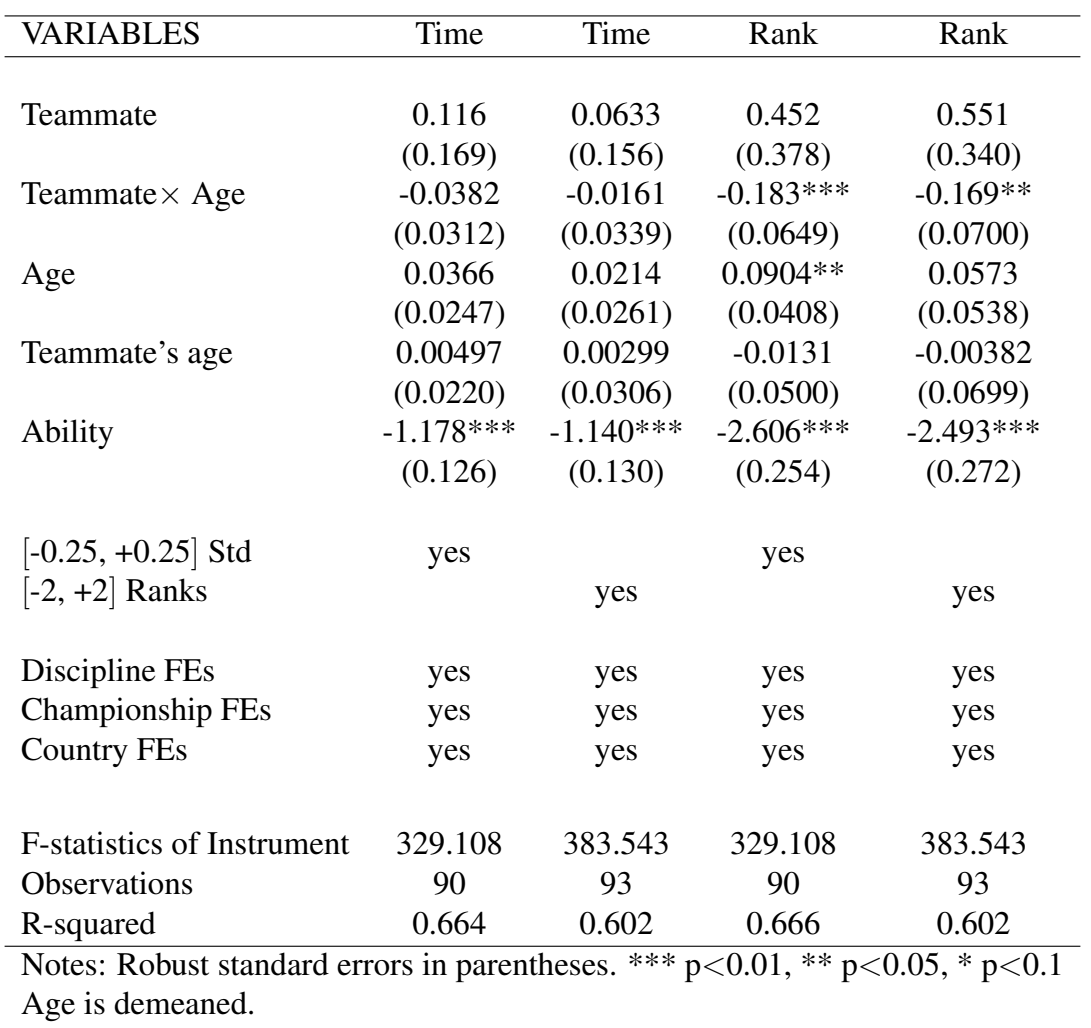


Table A5: Heterogeneity in experience

Panel A: Female

\begin{tabular}{lcccc}
\hline & $(1)$ & $(2)$ & $(3)$ & $(4)$ \\
VARIABLES & Time & Time & Rank & Rank \\
\hline \multirow{2}{*}{ Teammate } & $-0.490^{* *}$ & $-0.383^{* *}$ & $-1.071^{* *}$ & $-0.731^{* *}$ \\
& $(0.232)$ & $(0.164)$ & $(0.456)$ & $(0.330)$ \\
Teammate $\times$ Experience & 0.00496 & 0.0421 & 0.107 & $0.276^{*}$ \\
& $(0.100)$ & $(0.0743)$ & $(0.197)$ & $(0.142)$ \\
Experience & -0.0819 & $-0.145^{* *}$ & -0.173 & $-0.303^{* * *}$ \\
& $(0.109)$ & $(0.0577)$ & $(0.180)$ & $(0.103)$ \\
Age & -0.00392 & -0.0347 & -0.0251 & -0.0798 \\
& $(0.0400)$ & $(0.0372)$ & $(0.0631)$ & $(0.0613)$ \\
Teammate's age & -0.00164 & 0.00505 & 0.00602 & -0.00191 \\
& $(0.0253)$ & $(0.0241)$ & $(0.0646)$ & $(0.0493)$ \\
Ability & $-0.959 * * *$ & $-1.132^{* * *}$ & $-1.777 * * *$ & $-2.134 * *$ \\
& $(0.119)$ & $(0.122)$ & $(0.247)$ & $(0.258)$ \\
& & & & \\
[-0.25, +0.25] Std & yes & & yes & \\
{$[-2,+2]$ Ranks } & & yes & & yes \\
& & & & \\
Discipline FEs & yes & yes & yes & yes \\
Championship FEs & yes & yes & yes & yes \\
Country FEs & yes & yes & yes & yes \\
& & & & \\
F-statistics of Instrument & 135.831 & 195.503 & 135.831 & 195.503 \\
Observations & 97 & 95 & 97 & 95 \\
R-squared & 0.467 & 0.507 & 0.392 & 0.481 \\
\hline \hline
\end{tabular}

Panel B: Male

\begin{tabular}{|c|c|c|c|c|}
\hline VARIABLES & Time & Time & Rank & Rank \\
\hline Teammate & $\begin{array}{c}0.00791 \\
(0.141)\end{array}$ & $\begin{array}{l}-0.0748 \\
(0.142)\end{array}$ & $\begin{array}{c}0.188 \\
(0.348)\end{array}$ & $\begin{array}{c}0.251 \\
(0.348)\end{array}$ \\
\hline Teammate $\times$ Experience & $\begin{array}{c}0.0150 \\
(0.0468)\end{array}$ & $\begin{array}{c}0.0319 \\
(0.0363)\end{array}$ & $\begin{array}{c}0.0327 \\
(0.0928)\end{array}$ & $\begin{array}{c}0.0458 \\
(0.0824)\end{array}$ \\
\hline Experience & $\begin{array}{c}-0.0782 * \\
(0.0459)\end{array}$ & $\begin{array}{c}-0.0930 * * \\
(0.0373)\end{array}$ & $\begin{array}{l}-0.124 * \\
(0.0729)\end{array}$ & $\begin{array}{l}-0.116^{*} \\
(0.0669)\end{array}$ \\
\hline Age & $\begin{array}{c}0.0279 \\
(0.0190)\end{array}$ & $\begin{array}{l}0.0381^{*} \\
(0.0209)\end{array}$ & $\begin{array}{c}0.0109 \\
(0.0384)\end{array}$ & $\begin{array}{l}0.00737 \\
(0.0461)\end{array}$ \\
\hline Teammate's age & $\begin{array}{c}0.0128 \\
(0.0208)\end{array}$ & $\begin{array}{r}-0.00123 \\
(0.0271)\end{array}$ & $\begin{array}{c}0.0138 \\
(0.0473)\end{array}$ & $\begin{array}{c}0.0159 \\
(0.0647)\end{array}$ \\
\hline Ability & $\begin{array}{c}-1.040 * * * \\
(0.133)\end{array}$ & $\begin{array}{c}-1.054 * * * \\
(0.123)\end{array}$ & $\begin{array}{c}-2.297 * * * \\
(0.286)\end{array}$ & $\begin{array}{c}-2.268 * * * \\
(0.282)\end{array}$ \\
\hline $\begin{array}{l}{[-0.25,+0.25] \text { Std }} \\
{[-2,+2] \text { Ranks }}\end{array}$ & yes & yes & yes & yes \\
\hline $\begin{array}{l}\text { Discipline FEs } \\
\text { Championship FEs } \\
\text { Country FEs }\end{array}$ & $\begin{array}{l}\text { yes } \\
\text { yes } \\
\text { yes }\end{array}$ & $\begin{array}{l}\text { yes } \\
\text { yes } \\
\text { yes }\end{array}$ & $\begin{array}{l}\text { yes } \\
\text { yes } \\
\text { yes }\end{array}$ & $\begin{array}{l}\text { yes } \\
\text { yes } \\
\text { yes }\end{array}$ \\
\hline $\begin{array}{l}\text { F-statistics of Instrument } \\
\text { Observations } \\
\text { R-squared }\end{array}$ & $\begin{array}{c}357.358 \\
90 \\
0.686\end{array}$ & $\begin{array}{c}379.436 \\
93 \\
0.642\end{array}$ & $\begin{array}{c}357.358 \\
90 \\
0.654\end{array}$ & $\begin{array}{c}379.436 \\
93 \\
0.591\end{array}$ \\
\hline
\end{tabular}


Table A6: Heterogeneity in semifinal rank

\begin{tabular}{|c|c|c|c|c|}
\hline \multicolumn{5}{|l|}{ Panel A: Female } \\
\hline & $(1)$ & $(2)$ & (3) & $(4)$ \\
\hline VARIABLES & Time & Time & Rank & Rank \\
\hline \multirow[t]{2}{*}{ Teammate } & $-0.550 * *$ & $-0.380 * *$ & $-1.098 * *$ & -0.553 \\
\hline & $(0.214)$ & $(0.180)$ & $(0.441)$ & $(0.358)$ \\
\hline \multirow{2}{*}{ Teammate $\times$ SF Rank } & 0.120 & 0.0523 & $0.328^{*}$ & -0.0160 \\
\hline & $(0.100)$ & $(0.0794)$ & $(0.188)$ & $(0.161)$ \\
\hline \multirow[t]{2}{*}{ SF Rank } & -0.0383 & 0.0331 & 0.158 & $0.437 * * *$ \\
\hline & $(0.0823)$ & $(0.0799)$ & $(0.172)$ & $(0.166)$ \\
\hline \multirow[t]{2}{*}{ Age } & 0.00445 & -0.0370 & -0.00648 & -0.0819 \\
\hline & $(0.0354)$ & $(0.0401)$ & $(0.0566)$ & $(0.0658)$ \\
\hline \multirow[t]{2}{*}{ Teammate's age } & 0.00356 & 0.00229 & 0.0379 & 0.00839 \\
\hline & $(0.0305)$ & $(0.0251)$ & $(0.0664)$ & $(0.0462)$ \\
\hline$[-0.25,+0.25] \mathrm{Std}$ & yes & & yes & \\
\hline$[-2,+2]$ Ranks & & yes & & yes \\
\hline Discipline FEs & yes & yes & yes & yes \\
\hline Championship FEs & yes & yes & yes & yes \\
\hline Country FEs & yes & yes & yes & yes \\
\hline F-statistics of Instrument & 217.186 & 270.256 & 217.186 & 270.256 \\
\hline Observations & 97 & 95 & 97 & 95 \\
\hline R-squared & 0.461 & 0.475 & 0.441 & 0.499 \\
\hline
\end{tabular}

Panel B: Male

\begin{tabular}{|c|c|c|c|c|}
\hline VARIABLES & Time & Time & Rank & Rank \\
\hline Teammate & $\begin{array}{l}0.0972 \\
(0.161)\end{array}$ & $\begin{array}{c}-0.00756 \\
(0.157)\end{array}$ & $\begin{array}{c}0.369 \\
(0.347)\end{array}$ & $\begin{array}{c}0.240 \\
(0.328)\end{array}$ \\
\hline Teammate $\times$ SF Rank & $\begin{array}{c}0.0227 \\
(0.0651)\end{array}$ & $\begin{array}{l}-0.0792 \\
(0.0759)\end{array}$ & $\begin{array}{l}0.0469 \\
(0.126)\end{array}$ & $\begin{array}{l}-0.0322 \\
(0.136)\end{array}$ \\
\hline SF Rank & $\begin{array}{c}0.0605 \\
(0.0791)\end{array}$ & $\begin{array}{l}0.203 * * \\
(0.0848)\end{array}$ & $\begin{array}{c}0.388^{* *} \\
(0.154)\end{array}$ & $\begin{array}{c}0.741 * * * \\
(0.163)\end{array}$ \\
\hline Age & $\begin{array}{c}0.0226 \\
(0.0185)\end{array}$ & $\begin{array}{c}0.0355 \\
(0.0227)\end{array}$ & $\begin{array}{c}0.0308 \\
(0.0386)\end{array}$ & $\begin{array}{c}0.0470 \\
(0.0511)\end{array}$ \\
\hline Teammate's age & $\begin{array}{l}0.00803 \\
(0.0221)\end{array}$ & $\begin{array}{c}0.0106 \\
(0.0261)\end{array}$ & $\begin{array}{l}0.00492 \\
(0.0455)\end{array}$ & $\begin{array}{c}0.0438 \\
(0.0539)\end{array}$ \\
\hline $\begin{array}{l}{[-0.25,+0.25] \text { Std }} \\
{[-2,+2] \text { Ranks }}\end{array}$ & yes & yes & yes & yes \\
\hline $\begin{array}{l}\text { Discipline FEs } \\
\text { Championship FEs }\end{array}$ & $\begin{array}{l}\text { yes } \\
\text { yes }\end{array}$ & $\begin{array}{l}\text { yes } \\
\text { yes }\end{array}$ & $\begin{array}{l}\text { yes } \\
\text { yes }\end{array}$ & $\begin{array}{l}\text { yes } \\
\text { yes }\end{array}$ \\
\hline $\begin{array}{l}\text { F-statistics of Instrument } \\
\text { Observations } \\
\text { R-squared }\end{array}$ & $\begin{array}{c}217.985 \\
90 \\
0.666\end{array}$ & $\begin{array}{c}273.285 \\
93 \\
0.626\end{array}$ & $\begin{array}{c}217.985 \\
90 \\
0.681\end{array}$ & $\begin{array}{c}273.285 \\
93 \\
0.681\end{array}$ \\
\hline
\end{tabular}


Table A7: Heterogeneity in individualism score (IDV)

Panel A: Female

\begin{tabular}{lcccc}
\hline VARIABLES & $(1)$ & $(2)$ & $(3)$ & $(4)$ \\
Teammate & Time & Time & Rank & Rank \\
& $-0.507^{* *}$ & $-0.478^{* * *}$ & $-1.126^{* * *}$ & $-1.084^{* * *}$ \\
Teammate $\times$ IDV & $(0.224)$ & $(0.170)$ & $(0.433)$ & $(0.361)$ \\
& 0.0110 & 0.00974 & $0.0416^{*}$ & $0.0363^{*}$ \\
IDV & $(0.00998)$ & $(0.00806)$ & $(0.0215)$ & $(0.0193)$ \\
& -0.00584 & -0.00394 & -0.0151 & -0.00966 \\
Age & $(0.00825)$ & $(0.00571)$ & $(0.0166)$ & $(0.0131)$ \\
& -0.00170 & -0.0302 & 0.0152 & -0.0194 \\
Teammate's age & $(0.0364)$ & $(0.0361)$ & $(0.0663)$ & $(0.0656)$ \\
& 0.000907 & -0.000229 & 0.0192 & 0.00142 \\
Ability & $(0.0260)$ & $(0.0222)$ & $(0.0563)$ & $(0.0432)$ \\
& $-1.047 * * *$ & $-1.249 * * *$ & $-2.017 * * *$ & $-2.417^{* * *}$ \\
{$[-0.25,+0.25]$ Std } & $(0.152)$ & $(0.165)$ & $(0.273)$ & $(0.290)$ \\
{$[-2,+2]$ Ranks } & & & & \\
& yes & & yes & \\
Discipline FEs & & yes & & yes \\
Championship FEs & yes & yes & yes & yes \\
F-statistics of Instrument & 51.309 & 87.084 & 51.309 & 87.084 \\
Observations & 97 & 95 & 97 & 95 \\
R-squared & 0.417 & 0.466 & 0.324 & 0.404 \\
\hline \hline
\end{tabular}

Panel B: Male

\begin{tabular}{|c|c|c|c|c|}
\hline VARIABLES & Time & Time & Rank & Rank \\
\hline Teammate & $\begin{array}{l}0.0864 \\
(0.148)\end{array}$ & $\begin{array}{l}0.0921 \\
(0.156)\end{array}$ & $\begin{array}{c}0.439 \\
(0.340)\end{array}$ & $\begin{array}{c}0.482 \\
(0.345)\end{array}$ \\
\hline Teammate $\times$ IDV & $\begin{array}{c}0.00685 \\
(0.00755)\end{array}$ & $\begin{array}{c}0.0119^{*} \\
(0.00662)\end{array}$ & $\begin{array}{c}0.0154 \\
(0.0152)\end{array}$ & $\begin{array}{c}0.0203 \\
(0.0136)\end{array}$ \\
\hline IDV & $\begin{array}{l}-0.00305 \\
(0.00662)\end{array}$ & $\begin{array}{l}-0.00762 \\
(0.00504)\end{array}$ & $\begin{array}{l}-0.00806 \\
(0.0129)\end{array}$ & $\begin{array}{c}-0.0226 * * \\
(0.0104)\end{array}$ \\
\hline Age & $\begin{array}{c}0.0202 \\
(0.0198)\end{array}$ & $\begin{array}{c}0.0239 \\
(0.0181)\end{array}$ & $\begin{array}{c}0.0174 \\
(0.0401)\end{array}$ & $\begin{array}{c}0.0110 \\
(0.0399)\end{array}$ \\
\hline Teammate's age & $\begin{array}{l}0.00475 \\
(0.0224)\end{array}$ & $\begin{array}{l}0.00909 \\
(0.0256)\end{array}$ & $\begin{array}{c}0.0334 \\
(0.0552)\end{array}$ & $\begin{array}{c}0.0153 \\
(0.0626)\end{array}$ \\
\hline Ability & $\begin{array}{c}-1.175^{* * * *} \\
(0.113)\end{array}$ & $\begin{array}{c}-1.175^{* * * *} \\
(0.110)\end{array}$ & $\begin{array}{c}-2.453 * * * \\
(0.258)\end{array}$ & $\begin{array}{c}-2.353 * * * \\
(0.273)\end{array}$ \\
\hline $\begin{array}{l}{[-0.25,+0.25] \text { Std }} \\
{[-2,+2] \text { Ranks }}\end{array}$ & yes & yes & yes & yes \\
\hline $\begin{array}{l}\text { Discipline FEs } \\
\text { Championship FEs }\end{array}$ & $\begin{array}{l}\text { yes } \\
\text { yes }\end{array}$ & $\begin{array}{l}\text { yes } \\
\text { yes }\end{array}$ & $\begin{array}{l}\text { yes } \\
\text { yes }\end{array}$ & $\begin{array}{l}\text { yes } \\
\text { yes }\end{array}$ \\
\hline $\begin{array}{l}\text { F-statistics of Instrument } \\
\text { Observations } \\
\text { R-squared }\end{array}$ & $\begin{array}{c}194.770 \\
90 \\
0.666\end{array}$ & $\begin{array}{c}243.642 \\
93 \\
0.656\end{array}$ & $\begin{array}{c}194.770 \\
90 \\
0.653\end{array}$ & $\begin{array}{c}243.642 \\
93 \\
0.633\end{array}$ \\
\hline
\end{tabular}




\section{A.3 Other Tables}

Table A8: Characteristics of finalists, by teammate time

\begin{tabular}{lccc}
\hline & $\begin{array}{c}(1) \\
\text { Teammate's SF Time } \subset\end{array}$ & $\begin{array}{c}(2) \\
\text { Teammate's SF Time } \subset \\
\text { Median of Covariates }\end{array}$ & $\begin{array}{c}\text { Wilcoxon rank-sum test } \\
\text { [Cutoff, Cutoff }+0.25 \mathrm{std} \text {-value }\end{array}$ \\
\hline \hline Panel A: Female & & & 0.72 \\
\hline Age & 22 & 22 & 0.92 \\
No. Finals (Champ.) & 2 & 2 & 0.42 \\
No. Finals (Total) & 3 & 3 & 0.79 \\
Normalized time (SF) & 0.992 & 0.991 & \\
Total & 31 & 66 & 0.50 \\
\hline \hline Panel B: Male & & & 0.84 \\
& & & 062 \\
Age & 24 & 1 & 0.31 \\
No. Finals (Champ.) & 1 & 2 & \\
No. Finals (Total) & 2 & 0.994 & \\
Normalized time (SF) & 34 & 56 & \\
Total & & & \\
\hline
\end{tabular}

Table A9: Probability of winning a medal as outcome variable

\begin{tabular}{|c|c|c|c|c|}
\hline VARIABLES & $\begin{array}{c}(1) \\
\text { Eemale }\end{array}$ & $\begin{array}{c}(2) \\
\text { Eemale }\end{array}$ & (3) & (4) \\
\hline Teammate $(\mathrm{F})$ & $\begin{array}{c}0.479 * * * \\
(0.106)\end{array}$ & $\begin{array}{l}0.252 * * * \\
(0.0956)\end{array}$ & $\begin{array}{l}0.00290 \\
(0.0842)\end{array}$ & $\begin{array}{l}-0.0198 \\
(0.0815)\end{array}$ \\
\hline Age & $\begin{array}{l}-0.00537 \\
(0.0168)\end{array}$ & $\begin{array}{c}0.0174 \\
(0.0168)\end{array}$ & $\begin{array}{r}-0.00525 \\
(0.0115)\end{array}$ & $\begin{array}{r}-0.00530 \\
(0.0148)\end{array}$ \\
\hline Teammate's age & $\begin{array}{l}0.00626 \\
(0.0132)\end{array}$ & $\begin{array}{l}0.00362 \\
(0.0102)\end{array}$ & $\begin{array}{c}0.0109 \\
(0.0101)\end{array}$ & $\begin{array}{l}0.00309 \\
(0.0143)\end{array}$ \\
\hline Ability & $\begin{array}{l}0.355^{* * * *} \\
(0.0630)\end{array}$ & $\begin{array}{l}0.380 * * * \\
(0.0651)\end{array}$ & $\begin{array}{l}0.503 * * * \\
(0.0626)\end{array}$ & $\begin{array}{l}0.474 * * * \\
(0.0576)\end{array}$ \\
\hline Ability Heterogeneity & $\begin{array}{l}0.0629 \\
(0.246)\end{array}$ & $\begin{array}{c}0.197 \\
(0.222)\end{array}$ & $\begin{array}{l}-0.230 \\
(0.228)\end{array}$ & $\begin{array}{l}-0.127 \\
(0.207)\end{array}$ \\
\hline $\begin{array}{l}{[-0.25,+0.25] \text { Std }} \\
{[-2,+2] \text { Ranks }}\end{array}$ & yes & yes & yes & yes \\
\hline Controls & yes & yes & yes & yes \\
\hline Discipline FEs & yes & yes & yes & yes \\
\hline Championship FEs & yes & yes & yes & yes \\
\hline Country FEs & yes & yes & yes & yes \\
\hline Observations & 97 & 95 & 90 & 93 \\
\hline R-squared & 0.357 & 0.338 & 0.574 & 0.454 \\
\hline
\end{tabular}


Table A10: Two-stage least squares estimates of the effect of having a teammate in the final on the performance (standard errors clustered at individual level)

\begin{tabular}{|c|c|c|c|c|}
\hline \multicolumn{5}{|l|}{ Panel A: Female } \\
\hline VARIABLES & $\begin{array}{l}(1) \\
\text { Time }\end{array}$ & $\begin{array}{c}(2) \\
\text { Time }\end{array}$ & $\begin{array}{c}(3) \\
\text { Rank }\end{array}$ & $\begin{array}{c}(4) \\
\text { Rank }\end{array}$ \\
\hline Teammate $(\mathrm{F})$ & $\begin{array}{c}-0.602 * * * \\
(0.211)\end{array}$ & $\begin{array}{c}-0.448 * * * \\
(0.155)\end{array}$ & $\begin{array}{c}-1.187 * * \\
(0.486)\end{array}$ & $\begin{array}{c}-0.796 * * \\
(0.336)\end{array}$ \\
\hline Age & $\begin{array}{l}0.00261 \\
(0.0341)\end{array}$ & $\begin{array}{l}-0.0416 \\
(0.0378)\end{array}$ & $\begin{array}{l}-0.0169 \\
(0.0584)\end{array}$ & $\begin{array}{c}-0.0953 \\
(0.0619)\end{array}$ \\
\hline Teammate's age & $\begin{array}{l}-0.00670 \\
(0.0235)\end{array}$ & $\begin{array}{l}-0.00185 \\
(0.0216)\end{array}$ & $\begin{array}{l}0.00447 \\
(0.0605)\end{array}$ & $\begin{array}{c}-0.000181 \\
(0.0428)\end{array}$ \\
\hline Ability & $\begin{array}{c}-0.949 * * * \\
(0.137)\end{array}$ & $\begin{array}{c}-1.117 * * * \\
(0.142)\end{array}$ & $\begin{array}{c}-1.739 * * * \\
(0.261)\end{array}$ & $\begin{array}{c}-2.116^{* * * *} \\
(0.274)\end{array}$ \\
\hline Ability Heterogeneity & $\begin{array}{l}-0.447 \\
(0.591)\end{array}$ & $\begin{array}{l}-0.569 \\
(0.573)\end{array}$ & $\begin{array}{l}-0.328 \\
(0.905)\end{array}$ & $\begin{array}{l}-0.575 \\
(0.906)\end{array}$ \\
\hline $\begin{array}{l}{[-0.25,+0.25] \text { Std }} \\
{[-2,+2] \text { Ranks }}\end{array}$ & yes & yes & yes & yes \\
\hline Discipline FEs & yes & yes & yes & yes \\
\hline Championship FEs & yes & yes & yes & yes \\
\hline Country FEs & yes & yes & yes & yes \\
\hline F-statistics of Instrument & 508.550 & 525.496 & 4508.550 & 525.496 \\
\hline Observations & 97 & 95 & 97 & 95 \\
\hline R-squared & 0.457 & 0.481 & 0.389 & 0.457 \\
\hline
\end{tabular}

Panel B: Male

\begin{tabular}{lcccc}
\hline VARIABLES & Time & Time & Rank & Rank \\
\hline & & & & \\
Teammate (F) & 0.0596 & 0.00508 & 0.236 & 0.295 \\
& $(0.163)$ & $(0.146)$ & $(0.347)$ & $(0.319)$ \\
Age & 0.0208 & 0.0269 & 0.00493 & 0.00919 \\
& $(0.0155)$ & $(0.0185)$ & $(0.0351)$ & $(0.0501)$ \\
Teammate's age & 0.0133 & 0.00408 & 0.0193 & 0.0205 \\
& $(0.0218)$ & $(0.0273)$ & $(0.0478)$ & $(0.0649)$ \\
Ability & $-1.273^{* * *}$ & $-1.224^{* * *}$ & $-2.800^{* * *}$ & $-2.595^{* * *}$ \\
& $(0.126)$ & $(0.123)$ & $(0.247)$ & $(0.272)$ \\
Ability Heterogeneity & $0.795^{*}$ & $0.780^{*}$ & $2.144^{* *}$ & $1.927^{* *}$ \\
& $(0.437)$ & $(0.439)$ & $(0.930)$ & $(0.981)$ \\
& & & & \\
[-0.25, +0.25] Std & yes & & yes & \\
[-2, +2] Ranks & & yes & & yes \\
& & & & \\
Discipline FEs & yes & yes & yes & yes \\
Championship FEs & yes & yes & yes & yes \\
Country FEs & yes & yes & yes & yes \\
& & & & \\
F-statistics of Instrument & 676.051 & 797.344 & 676.051 & 797.344 \\
Observations & 90 & 93 & 90 & 93 \\
R-squared & 0.671 & 0.618 & 0.660 & 0.599 \\
\hline
\end{tabular}

Notes: Standard errors clustered at individual level in parentheses.

$* * * \mathrm{p}<0.01, * * \mathrm{p}<0.05, * \mathrm{p}<0.1$

Normalized time is the ratio of the own time in the final over the average time of the sixteen athletes in the semifinal, and multiplied by 100 . 